\title{
Rational Health Policy and the Legal Standard of Care: A Call for Judicial Deference to Medical Practice Guidelines
}

\author{
Richard E. Leahy $\dagger$
}

The expanding application of sophisticated technology to medical practice, and its attendant costs, has created the need for medical practice guidelines for physicians. It remains unclear, however, which authorities should be responsible for developing these guidelines, and how these guidelines should be received by courts when adjudicating medical negligence claims. This Comment addresses these issues, and contends that professional medical societies are the most appropriate authorities for developing and promulgating practice guidelines. It further contends that courts should recognize and give legal force to such guidelines by taking judicial notice of relevant medical practice guidelines, and instructing juries on the legal standard of care accordingly. The author bases his position on a variety of public health and public policy grounds.

\section{INTRODUCTION}

Medical authorities, regulatory bodies, and underwriters increasingly recognize the need for standardized inedical practice gnidelines. ${ }^{1}$ This recognition stems from two basic observations. First, the allocation

$\dagger$ B.S. 1979, College of William and Mary; M.D. 1984, University of Virginia; J.D. candidate 1990, Boalt Hall School of Law, University of California, Berkeley. The author thanks Einer Elhauge, Scott Parker, Steven Rinkle, Juliet Browne, and David McGowan for their valuable criticisms of drafts of this Comment. A special thanks to Linda Leahy for her limitless support during the editorial process, and beyond.

1. See generally Institute of Medicine, Assessing Medical Technologies 309-10 (1985) [hereinafter IOM STUDY] (describing the development and use of Medical Necessity Program guidelines by the Blue Cross and Blue Shield Association); NATIONAL LEADERSHIP COMm'N ON Health Care, For the Health of a Nation 58, 62 (1989) [hereniafter Leadership COMMISSION REPORT] (recommending a "National Quality Improvement Imitiative" and the creation of a national medical database); Lee, Ginsburg, LeRoy \& Hammons, The Physician Payment Review Commission Report to Congress, 261 J. A.M.A. 2382, 2385 (1989) ("recommend[nig] that the federal government actively encourage the development and dissemination of practice guidelines"); Am. Med. News, July 7, 1989, at 15, col. 1 (reporting AMA's priority of developing practice guidelines as a means of controlling Medicare spending).

Practice guidelines are recommendations or statements about the management of specific clinical problems in a specific class of patients, promulgated by expert nedical authorities. For further description, see infra text accompanying notes 21-41. See also LEADERSHIP COMMISSION REPORT, supra, at 156-57. 
of medical services varies widely by geographic region. ${ }^{2}$ These variations generally fail to correspond to any regional differences in medical need, but rather seem to be determined by physicians' uncertainties about how to approach certain medical probleins ${ }^{3}$ and their tendency to conform to the practice patterns of local colleagues. ${ }^{4}$ These practice variations frequently entail marked differences in cost, but increased costs and the social objective of maximizing health benefits may be poorly correlated. ${ }^{5}$

Second, even when consensus on practice style exists, there is often no clearly articulated theoretical basis for costly clinical practices. ${ }^{6}$ Practice standards frequently are based upon a combination of limited clinical studies, unverified beliefs, and professional traditions, ${ }^{7}$ ratlier than upon reliable data. Because of the unacceptably high cost of inedical care in the Umited States, ${ }^{8}$ concerned groups are reassessing the process by which medical practice patterns are establislied. Policy makers are currently designing and implementing quality assessment programs and

2. See, e.g., Chassin, Brook, Park, Keesey, Fink, Kosecoff, Kahn, Merrick \& Solomon, Variations in the Use of Medical and Surgical Services by the Medicare Population, 314 NEW ENG. J. MED. 285, 287 (1986) (documenting "large geographic variations in the rates of use of many different medical and surgical services" by Medicare beneficiaries); Wennberg, Dealing With Medical Practice Variations: A Proposal for Action, HeAlTH AFfaIrs, Summer 1984, at 6, 9-15 (discussing results of various New England-based studies of practice variation); see also Eddy, Variations in Physician Practice: The Role of Uncertainty, HEALTH AFFAIRS, Fall 1984, at 74 (suggesting factors influencing practice variations).

3. LEADERSHIP COMMISSION REPORT, supra note 1, at 16-17; see also Schwartz, The Role of Professional Medical Societies in Reducing Practice Variations, Health AFFAIRS, Fall 1984, at 90, 94 (citing insufficient information, inadequate access to professional literature, and lack of professional consensus as reasons for variations in service use).

4. Office of Technology Assessment, Strategies for Medical Technology ASSESSMENT 73 (1982) [hereinafter OTA REPORT II] (physicians cite professional colleagues more often than the professional literature as sources they turn to when deciding to use a new procedurc for first time); Eddy, supra note 2, at 85-86.

5. Weinstein \& Stason, Foundations of Cost-Effectiveness Analysis for Health and Medical Practices, 296 NEw ENG. J. MED. 716, 716 (1977).

6. See OTA REPORT II, supra note 4, at 5 ("[T] here is not enough information available about safety, efficacy, costs, and social values of medical technologies; much existing information is of dubious quality and is therefore unreliable ....").

7. See Greer, The State of the Art Versus the State of the Science: The Diffusion of New Medical Technologies into Practice, 4 INT'L J. Tech. Assessment Health Care 5 (1988) (describing physician skepticism of new procedures and reliance upon tradition).

8. Expenditures on health care in 1987 were greater than $\$ 500$ billion (11\% of the United States gross national product); some estimates of 1989 costs exceed $\$ 600$ billion. Sullivan, Shattuck Lecture - The Health Care Priorities of the Bush Administration, 321 NEw ENG. J. MED. 125, 127 (1989). By comparison, expenditures in 1981 were $\$ 287$ billion, and, in $1965, \$ 42$ billion. Mehlman, Rationing Expensive Lifesaving Medical Treatments, 1985 WIS. L. REv. 239, 239. Expressed as per capita outlay in constant dollars, national health care expenditures increased $133 \%$ from 1960 through 1986. Ginzberg, A Hard Look At Cost Containment, 316 NEw ENG. J. MED. 1151, 1151 (1987); see also Am. Med. News, Aug. 18, 1989, at 1, col. 1 (noting that Medicaid spending by states jumped by more than $100 \%$ during the $1980 \mathrm{~s}$ ). One panel of economic and financial experts predicts that by 1995, spending for the nation's health care will reach $13.3 \%$ of the gross national product. 17 Health Law. News Rep., Aug. 1989, at 4. 
cost-effectiveness analyses to redress this pattern of inefficient allocation and wasteful spending. ${ }^{9}$

The litigious atınosphere of inodern inedical practice contributes to soaring medical costs. As the number of lawsuits filed ${ }^{10}$ and the amounts of awards climb, ${ }^{11}$ malpractice premiums increase correspondingly. ${ }^{12}$ Ultimately, these costs are borne by consumers, though usually indirectly, in the form of inore expensive medical care. ${ }^{13}$ Increased insurance costs have resulted in decreased access to critical forms of inedical care in many areas. ${ }^{14}$ Further, physicians sensitized to the threat of malpractice hitigation are more likely to practice "defensive medicine," 15 by perform-

9. See OTA REPORT II, supra note 4, at 190 (noting need for a "single organized and adequately funded program or agency" charged with duty to assess new technologies, and suggesting creation by insurers of joint fund to finance such a program). For a summary and general description of various federal, state, and private sector organizations involved im medical technology assessment and practice guidelines development, see Goodman, A Practical Guide to Technology Assessment, Business \& HEALTH, Aug. 1987, at 14, 16-19. In addition, Congress has recently established a new administrative body, the Agency for Health Care Policy and Research, and charged it with the duty, among others, of assessing the effectiveness, efficiency, and quality of health care services. Omnibus Budget Reconciliation Act of 1989, Pub. L. No. 101-239, $\S 6103$ (to be codified at 42 U.S.C. $\$ 901$ ).

10. In some states, including California, New York and Florida, it is estimated that one claim is filed for every three or four physicians. U.S. GEN. Accounting OFfice, Medical Malpractice: Six State Case Studies Show Claims and INSURance Costs Still Rise DESPITE REFORMS 17 (1986) (using 1984 figures). In 1968 the national average was one claim per thirty-seven physicians; by 1975 the leading malpractice insurer was reporting a rate of one claim for every eight physicians. P. Danzon, Medical Malpractice: Theory, Evidence, and Public PoLICY 60 (1985).

11. Between 1975 and 1985 , the average medical malpractice jury award increased from $\$ 220,108$ to $\$ 1,017,716$. U.S. DEP'T OF JUSTICE, REPORT OF THE TORT POLICY WorkING GROUP on the Causes, Extent and Policy Implications of the Current Crisis in Insurance AVAILABILITY AND AFFORDABILITY 35-36 (1986). Similarly, in 1975 there were 3 million-dollar medical malpractice verdicts; in 1984 the number had grown to 71 . Id.

12. Between 1965 and 1971 , professional liability insurance in California increased up to $600 \%$ generally, and up to 950\% for surgeons. American Medical Ass'n Special Task Force ON Professional Liab. and INS., Professional Liability in the '80s: Report 1, at 4 (1985) [hereinafter AMA, Professional Liabilitry]. Between 1975 and 1983, medical liability premiums continued to increase by more than $80 \%$ in general. Id. at 8,

13. LEADERSHIP COMMISSION REPORT, supra note 1 , at xxvii.

14. Id. at 67.

15. "Defensive medicine," the practice of ordering tests or providing medical care solely to avoid possible litigation, has perhaps been encouraged by courts that assume the posture that if a test exists, it ought to be ordered. See Wilkinson v. Vesey, 110 R.I. 606, 615-16, 295 A.2d 676, 683 (1972) ("If a physician, as an aid to diagnosis, does not avail himself of all of the scientific means and facilities available to him ... such an omission can be considered as evidence of negligence."); see also O'Connell, Neo-No-Fault Remedies for Medical Injuries: Coordinated Statutory and Contractual Alternatives, LAw \& CONTEMP. ProBs., Spring 1986, at 125, 125 (describing how health care providers' perceptions of the legal system as a game of chance provide incentives to practice defensive medicine).

Many practitioners perceive that the likelihood of being sued and found guilty of malpractice bears little relation to either the quality of care provided or to actual fault. This perception seems to be confirmed by at least one recent study. See Cheney, Posner, Caplan \& Ward, Standard of Care and Anesthesia Liability, 261 J. A.M.A. 1599 (1989) (anesthesiologists stand greater than $40 \%$ 
ing tests in excess of those inedically indicated, to create a record in anticipation of litigation. ${ }^{16}$ Although it is inpossible to determine precisely the extent to which defensive inedicine increases inedical costs, these costs are clearly significant. ${ }^{17}$

As practice guidelines and malpractice reforms continue to develop, ${ }^{18}$ it remains uncertam how these two policy trends will be integrated. In particular, how will inedical practice standards or guidelines, once estabhished, impact the medical standard of care at law? Can physicians implement such guidelines without substantially increasing their inalpractice liability exposure? Will courts recognize and enforce the societal policies that underlie practice guidelines when faced with individual "bad-outcome" cases? This Comment addresses these issues and proposes that, when promulgated by appropriate inedical authority, ${ }^{19}$ courts should take judicial notice of relevant practice guidelines as the legal standard of care. ${ }^{20}$ This procedure for determining the standard of care will facilitate a inore accurate fit between the legal standard and actual inedical standards than the current inethod of charging juries with the task of assessing expert testimony; sinultaneously, it will reinforce important societal health care pohicies.

Part I of this Comment explains how sophisticated and expensive teclinology, coinbined with the information explosion in medicine, has

chance of having to pay out on malpractice claims despite providing appropriate care as determined by panel of experts); $c f$. Johnson, Phillips, Orentlicher \& Hatlie, A Fault-Based Administrative Alternative For Resolving Medical Malpractice Claims, 42 VAND. L. REV. 1365, 1371 (1989) ("[N]egligent behavior is not closely related to the likelihood of paying an injured victim .....").

16. See LEADERSH1P COMMISSION REPORT, supra note 1, at 67-68.

17. Relman, The National Leadership Commission's Health Care Plan, 320 New ENG. J. MED. 314, 315 (1989) ("There can be no doubt that fear of litigation drives many physicians to wasteful styles of practice, which, when added to the ever-increasing premiums for liability insurance, contribute to the rising costs of health care."); Robbins \& Rose, Partial Thromboplastin Time as a Screening Test, 90 ANNALS INTERNAL MED. 796, 796 (1979) ("With the growth of litigation ... physicians have adopted routine procedures that may add significantly to the cost of medical care."). In 1984, an AMA task force estimated that the practice of defensive medicine may add "anywhere from $\$ 15$ billion to $\$ 40$ billion annually to health care costs." AMA, ProfessionAL L1ABILITY, supra note 12, at 3; see also 17 Health Law. News Rep., July 1989, at 5 (reporting estimates for defensive medicine and other indirect malpractice costs of between $\$ 12$ billion and \$14 billion).

18. Indeed, every state has enacted some type of tort reform in response to the medical malpractice crisis. U.S. GEN. Accounting OFFICE, supra note 10, at 9; W. VA. CODE \$§ 55-7B-1 to 55-7B-11 (Supp. 1989).

19. This Comment argues that professional medical societies are at present the most appropriate authorities for developing practice guidelines. See infra text aceompanying notes 12140.

20. Generally, practice guidelines will be "relevant" if they are designed to cover the clinical situation at issue in a given ease. For many clinical fact patterns there may be no guidelines yet developed, in which case the policy question of legal recognition and enforcement is not prescnted. As more data is collected and guidelines become more prevalent, however, courts will face this issue more frequently. 
created the need for practice guidelines. In addition, Part I contends that important social pohicy goals will be served by the implementation of such guidelines, and it details the characteristics of various categories of practice guidelines. Part II examines the traditional method of using expert testiinony to determine the legal standard of care, and argues that this method may undermine the impleinentation of practice guidelines and the policy concerns that they address. Part III sets forth the policy advantages of the proposal that courts take judicial notice of practice guidelines and instruct juries on the legal standard of care accordingly. Part IV argues that professional medical societies are presently the most appropriate authorities for promulgating practice guidelines, and that such organizations must have a substantial role in any medical practice policy-making body estabhished in the future. Part V examines the methodology used by medical societies for developing practice guidelines, with particular attention to cost-effectiveness analysis. The legal notion of proximate cause is then briefiy compared to the scientific probabilistic approach to causation in order to illustrate the conceptual shortcomings of traditional inalpractice law when apphed to cases involving practice guideline impleinentation. Finally, Part VI sets forth in detail the procedural and substantive advantages of using judicial notice as the ineans to give legal force to practice guidelines.

\section{I}

\section{The NeEd for Practice Guidelines}

In recent decades, the role of science in medical care has increased dramatically. Rapid advances in such fields as cell biology, immunology and pharmacology have been accoinpamed by a inarked expansion in the application of high teclinology to inedical practice. The diagnostic power of such developinents as computerized tomography, endoscopy, radionuclide scanning, and magnetic resonance imaging have tended to discredit and displace the physician's traditional diagnostic methods in many areas. ${ }^{21}$ Similarly, an impressive array of laboratory tests have been developed that permit the physician to inake otherwise elusive diagnoses by analyzing small samples of blood or tissue. ${ }^{22}$

21. See, e.g., Black \& Friedman, Ultrasound Examination in the Patient with Ascites, 110 ANNALS INTERNAL MED. 253, 253 (1989) (noting that noninvasive imaging techniques have repeatedly demonstrated the unreliability of clinical diagnoses of ascites and liver size); Huisman, Buller, ten Cate, Heijermans, van der Laan \& van Maanen, Management of Clinically Suspected Acute Venous Thrombosis in Outpatients With Serial Impedance Plethysmography in a Community Hospital Setting, 149 ARCHIVES INTERNAL MED. 511, 511 (1989) (reporting that only approximately $45 \%$ of patients suspected of having acute deep venous thrombosis on clinical grounds in fact have it, as determined by plethysmography). See generally Am. Med. News, Jan. 5 , 1990, at 30, col. 1 (outlining the wide range of technological advances in medicine in the 1980s).

22. See generally J. Henry, Clinical Diagnosis and Management by Laboratory METHODS (17th ed. 1984). 
New technology also has revolutionized medical therapeutics. Many surgical procedures have become virtually bloodless by the use of lasers, ${ }^{23}$ and many conditions previously treatable only by surgery are now treated effectively by using endoscopes or ultrasound. ${ }^{24}$ The arsenal of pharmacologic agents at the physician's disposal similarly has increased dramatically. ${ }^{25}$

These advances have been impressive, but because they have been accompanied by staggering increases in medical costs, ${ }^{26}$ the efficacy and cost-efficiency of this new style of medical practice has been increasingly scrutimized. Critics note that expensive new technology is often adopted uncritically, before its efficacy is adequately evaluated. ${ }^{27}$ Conversely, new information reported in scientific literature often fails to translate into new practice styles. ${ }^{28}$

Because of this apparent lack of coordination between technology assessment and clinical practice, ${ }^{29}$ the medical profession, ${ }^{30}$ private insurers, ${ }^{31}$ and the federal government ${ }^{32}$ have begun to develop reliable

23. See, e.g., Dixon, Current Laser Applications in General Surgery, 207 ANNALS SURGERY 355 (1988); Litvak, Grundfest, Papaiannou, Mohr, Jakubowski \& Forrester, Role of Laser and Thermal Ablation Devices in the Treatment of Vascular Diseases, 61 AM. J. CARdiology 81G (1988).

24. See, e.g., C. Cotton \& M. Sleisenger, Practical Gastrointestinal Endoscopy (2d ed. 1982); D. Rice, Endoscopic Paranasal Sinus Surgery (1988); S. Hagen-ANSERT, TEXTBOOK OF Diagnostic Ultrasonography (3d ed. 1989).

25. See generally Goodman \& Gilman's The Pharmacological Basis of Therapeutics (7th ed. 1985).

26. See supra note 8.

27. Office of TeChNology Assessment, Assessing the EfFicacy and SAFETy of Medical TeChNologies 93-94 (1978) [hereinafter OTA REPORT I]; Greer, supra note 7, at 5-6 ("Technologies believed to be efficacious are often very slow in achieving an impact, while technologies of questionable value diffuse rapidly ....").

28. Greer, supra note 7, at 5; see Huth, The Underused Medical Literature, 110 ANNALS INTERNAL MED. 99, 99 (1989) (citing "time and effort" involved in obtaining information from the literature as the main barrier to incorporation into practice). Note, however, that reticence by practitioners blindly to accept assertions made in scientific publications sometimes may be justified. See OTA REPORT I, supra note 27, at 92.

29. OTA REPORT I, supra note 27 , at $89-90$.

30. See, e.g., Schwartz, Ball \& Moser, Safety, Efficacy, and Effectiveness of Clinical Practices: A New Initiative, 96 ANNALS INTERNAL MED. 246 (1982) (describing the Clinical Efficacy Assessment Project of the American College of Physicians, intended "to determine the medical merit of selected practices in internal medicine"); Am. Med. News, supra note 8, at 1, col. 1 (reporting AMA and American Society of Internal Medicine endorsement of practice guidelines as alternative to expenditure targets); id. at 63 , col. 4 (noting that 21 national medical specialty societies to date have developed practice guidelines).

31. IOM STUdY, supra note 1, at 309-10 (describing the Medical Necessity Program of Blue Cross and Blue Shield Association).

32. The Department of Hcalth and Human Services (HHS) has announced its intention to play an active role, through the Health Care Financing Administration (HCFA) and the Public Health Service, in improving the quality of information that guides medical practice. Roper, Winkenwerder, Hackbarth \& Krakauer, Effectiveness in Health Care: An Initiative to Evaluate and Improve Medical Practice, 319 NEw ENG. J. MED. 1197, 1197 (1988). In keeping with this policy, 
methods to evaluate the efficacy and cost-efficiency of various forms of medical practice. These studies have already led to the development and endorsement of a wide range of recommended practice guidelines, both for screening ${ }^{33}$ and diagnostic testing, ${ }^{34}$ and for medical treatments. ${ }^{35}$

Questions regarding the appropriate use of new tests and procedures commonly arise in the technology-oriented atmosphere of modern medicme. ${ }^{36}$ It is impractical, however, for individual physicians to address these questions independently. Sound judgments concerning the appropriate use of new technology require expertise in medical practice, climical epidemiology, statistics, and decision analysis, as well as technical familiarity with the specific technology at issue. This breadth of expertise is beyond the scope of most physicians' traiming. ${ }^{37}$

the Public Health Service has recently made efforts "to evaluate patient outcomes in order to determine the appropriateness of medical treatments and surgical procedures; to assemble data bases and improve research methods used to evaluate patient outcomes; and to develop mechanisms to disseminate and encourage the adoption of chinically useful information." Id. at 1200.

In another federally sponsored effort to address the efficacy of health technology, Congress established the Council of Health Care Technology. Health Promotion and Disease Prevention Amendments of 1984, Pub. L. No. 98-551, 98 Stat. 2815, 2820-22 (1984), amended by Health Services Amendments of 1985, Pub. L. No. 99-117, 99 Stat. 491, $493-94$ (1985); see Division of Health Sciences Policy, Inst. of Medicine, A Consortium for Assessing Medical Technology: Planning Study Report (1983). More recently, Congress has established the Agency for Health Care Pohcy and Research. See supra note 9; see also Bunker, Fowles \& Schaffarzick, Evaluation of Medical-Technology Strategies: Effects of Coverage and Reimbursement, 306 NEw ENG. J. MED. 620, 620-24 (1982) (first of two parts); Bunker, Fowles \& Schaffarzick, Evaluation of Medical-Technology Strategies: Proposal for an Institute for Health Care Evaluation, 306 NEw ENG. J. MED. 687, 687-92 (1982) (second of two parts) (describing public debate regarding need for an institute for health eare evaluation) [hereinafter Bunker, Proposal].

33. See, e.g., Oboler \& LaForce, The Periodic Physical Examination in Asymptomatic Adults, 110 ANNALS INTERNAL MED. 214 (1989).

34. See, e.g., Health and Policy Comm., Am. College of Physicians, How to Study the Gallbladder, 109 ANNAls INTERNal MEd. 752 (1988) [heremafter Health and Policy Comm., Gallbladder].

35. See, e.g., 1988 Joint National Committee, The 1988 Report of the Joint National Committee on Detection, Evaluation, and Treatment of High Blood Pressure, 148 ARCHIVES INTERNAL MED. 1023 (1988) [hereinafter Blood Pressure Report ].

36. For example, the approach to the diagnosis of gallbladder abnormalities entails decisions regarding tire use of the following available diagnostic tests: ultrasonography, cholescintigraphy, oral cholecystography, endoscopic retrograde cholangiopancreatography, and percutaneous gallbladder puncture. Health and Policy Comm., Gallbladder, supra note 34, at 752-53.

Similarly, the diagnostic approach to earotid artery disease requires choosing among the following tests: duplex ultrasonography, carotid doppler ultrasound, periorbital doppler ultrasound, oculoplethysmography, digital subtraction angiography, conventional carotid angiography, and intraarterial digital subtraction angiography. Health and Policy Comm., Am. College of Pliysicians, Diagnostic Evaluation of the Carotid Arteries, 109 ANNALS INTERNAL MED. 835, 836-37 (1988) [hereinafter Health and Policy Comm., Carotid Arteries].

37. Sclrwartz, Ball \& Moser, supra note 30, at 246. For a discussion of the degree of complexity involved in idealized medical decisionmaking, see Eddy, supra note 2, at 83-85; Eddy, Clinical Policies and the Quality of Clinical Practice, 307 NEw ENG. J. MED. 343, 343 (1982). For further discussions of the cognitive aspects of diagnostic reasoming, see Kassirer, Diagnostic Reasoning, 110 ANNAls INTERNal MED. 893 (1989); Moskowitz, Kuipers \& Kassirer, Dealing 
Furthermore, even if practicing physicians possessed these analytic skills, it is clear that insufficient time is available to permit a case-by-case approach to so many decisions. Indeed, redundant decisionmaking efforts by individual physicians would be inefficient and unlikely to result in any degree of uniformity. ${ }^{38}$ Also, experts increasingly recognize that the raw data prerequisite to sound clinical decisionmaking is frequently unavailable. ${ }^{39}$ Thus, even assuming that the average practitioner could analyze the data competently, the paucity of rehable data upon which such analyses must be based wonld render any conclusions suspect.

Finally, the recognized importance of factoring economic considerations into medical decisionmaking is ethically troublesome for physicians dealing with individual patients. ${ }^{40}$ Beyond this substantial ethical dilemma, it is also clear that few physicians possess the necessary exper-

With Uncertainty, Risks, and Tradeoffs in Clinical Decisions, 108 ANNAls INTERNAl MEd. 435 (1988).

38. Of course, some variation in practice patterns is necessary and appropriate. The differences between individual patients, the degrees of skill and experience of individual physicians, and the variances between available facilities require such ranges of practice. See Eddy, supra note 2, at 86 ("some variation in practice is appropriate... [t] the problem is that uncertainty so clouds every aspect of this problem that many of the appropriate variations cannot occur, and many of the variations we see are not motivated by logic or a deep understanding of the issues").

39. LEADERSHIP COMMISSION REPORT, supra note 1, at 16-18 (underlying reason for wide practice variations is an "inadequate scientific base for clinical decisionmaking"); OTA REPORT II, supra note 4, at 189 ("The just distribution of efficacious medical care ... requires better data than the data currently available."); Bunker, Proposal, supra note 32, at 689 ("The number of current clinical trials [primarily funded by the NIH] ... is probably small in proportion to need."); O'Leary, Quality Assessment: Moving From Theory to Practice, 260 J. A.M.A. 1760, 1760 (1988) ("epidemiology is in its infancy; we do not yet have a database to underpin our formulations and determinations"); Roper, Winkenwerder, Hackbarth \& Krakauer, supra note 32, at 1197 (stating that data supporting the use of many new medical practices is often lacking or based on flawed research).

40. Much has been written about this dileınına, in which physicians feel a primary responsibility to do whatever is best for their individual patient, regardless of the costs, but simultaneously feel pressures to cut costs. These pressures inay be applied by prospective payment systems, HMO management decisions, third-party payors directly, and others. See, e.g., Daniels, Why Saying No To Patients in the United States Is So Hard: Cost Containment, Justice, and Provider Autonomy, 314 NEW ENG. J. MED. 1380 (1986) (discussing inoral aspect of cost-containment measures); Stone, Law's Infiuence on Medicine and Medical Ethics, 312 NEw ENG. J. MED. 309, 312 (1985) (outlining the medical profession's confusion about the relationship between traditional ethical principles and new deunands to reduce costs); Thurow, Learning To Say "No," 311 NEw ENG. J. MED. 1569 (1984) (urging expansion of professional norms to increase cost controls).

In addition, the threat of malpractice liability looms constant in the minds of many physicians, and a jury faced with a "bad outcome" case is not likely to be persuaded by attempts to justify a course of action by pointing out the need to save societal health care resources. As one commentator notes:

[A] formal legal concession to cost constraints is tantamount to denying that the poor are entitled to fair remedy for equivalent malpractice injuries. The same injury could represent a tort for a wealthy person, yet not a tort for an indigent patient .... Such an outcome would surely offend our society's egalitarian values.

Morreim, Cost Constraints as a Malpractice Defense, HASTINGS CENTER REP., Feb.-Mar. 1988, at 5, 8. 
tise in cost-effectiveness analysis independently to develop cost-effective policies. Indeed, the very notion of policy making entails centralization rather than individuation.

In sum, physicians are poorly positioned to make individually many of the decisions raised by the modern practice environment. Thus, rehable decisionmaking guidelines for these complex questions are vital to explicate the optimal inedical care for a given set of circunstances. ${ }^{41}$

\section{A. Medical Practice Guidelines Serve Important Policy Goals}

In addition to assisting physicians to make appropriate clinical decisions, thereby benefiting both physicians and patients, practice guidelines can increase the efficiency of the malpractice hitigation process. Attorneys-lacking medical expertise-may often have difficulty ascertaining whether a given practice is appropriate. Indeed, attorneys may be as confused by contradictory expert testimony as jurors. When clear guidelines are established, however, attorneys will be able to evaluate claims more coinpetently. This can decrease discovery time and save money on multiple expert consultations. Frivolous lawsuits can be dismissed quickly, and claims with merit more promptly settled.

Several other important societal goals are achieved when reliable, cost-effective practice guidelines are implemented. Most importantly, health care resources are allocated more efficiently by discouraging practice patterns that are costher, yet no more effective than available alternatives. Similarly, such guidelines will minimize the risk that physicians will engage in practices with marguial benefits that are outweighed by excessive costs or unacceptable risks. ${ }^{42}$

Practice guidelines also facilitate the societal goal of improving the quality of medical care, because outcome optnmization is a primary goal in fashioning guidelines. Properly estabhished and implemented guidelines will decrease the use of inappropriate and unnecessary procedures, leading to an overall decrease in the incidence of iatrogenic liarm. ${ }^{43}$ Also, when there is insufficient niformation to develop reliable practice guidelines in selected areas, the evaluation process helps identify and target these areas for further research. ${ }^{44}$ Data acquisition and assessment can then be focused on these areas to lielp develop guidehines in the future.

41. Of course, the notion of treatment guidelmes is far from radical. The development of prospective practice guidelines by medical authorities merely formalizes and improves a standard adjunct to medical decisionmaking. Doctors, by necessity, have always had occasion to defer to the judgment of other expert physicians.

42. For an estimate of the potential savings that would be generated by implementing practice guidelines, see LEADERSHIP COMMISSION REPORT, supra note 1, at 125-26.

43. LEADERSHIP COMMISSION REPORT, supra note 1, at 18-19.

44. Schwartz, supra note 3 , at 95. 


\section{B. Types of Practice Guidelines}

Practice guidelines can be divided into three categories: diagnostic, screening, and treatment guidelines. The relative characteristics of each will affect the ease with which they can be assimilated to the legal standard of medical care. Determining the indications for a screening test, for example, is a much less fact-specific inquiry than a diagnostic testing decision. This follows from the different nature of diagnostic and screening tests.

For example, diagnostic tests are used to determine the presence or absence of specific disorders in particular individuals with unique complaints and clinical findings. In choosing a diagnostic testing approach, a physician will have numerous factors to take into account-factors largely determined by the unique characteristics of an individual patient and the particular clinical circumstances. She may have to consider how sick the patient is, and how well the patient will tolerate various tests. Prior experience with the patient in similar circumstances, and the relative expense and invasiveness of alternative tests must also be considered in the approach to a diagnostic problem. Furthermore, the physician must consider how one test will affect the timing, and perhaps results, of a second test (which may or may not be indicated depending upon the results of the first). Additionally, testing may affect the continuation of ongoing medical therapy, further complicating the physician's decision. The relative reliability of alternative tests in the particular facility can be a key factor, as can the relative skill of the operators or technicians involved.

In contrast, screening tests are preventive in nature, and are designed to be performed on individuals that belong to a defined class (for example, females over the age of forty) and have no complaints or abnormal findings suggestive of the disease for which they are screened. When determining the indication for a screening test, therefore, a physician has very few factors to consider beyond the age and sex of the patient. ${ }^{45}$ Screening tests are by design well-tolerated and inexpensive, ${ }^{46}$

45. Factors relevant to a testing decision vary among tests. Some require eliciting ccrtain details from the clinical history, while others require a search for specific physical findings. These clinical findings, the presence and significance of which are subject to the clinical judgment of the individual physician, determine if a patient is a member of the subpopulation that should be screened.

46. The six criteria generally used for assessing the feasibility of a screening test were enumerated by Frame and Carlson in 1975: 1) the disease must have a marked effect on the quality or length of life, 2) acceptable methods of treatment must be available, 3) the disease must have an asymptomatic period during which detection and treatment markedly reduce morbidity or mortality, or both, 4) treatment in the asymptomatic period must yield a therapeutic result superior to that obtained by delaying treatment until symptoms appear, 5) tests must be available at a reasonable cost to detect the disease in the asymptomatic period, and 6) the incidence of the disease must be sufficient to justify the cost of screening. Frame \& Carlson, A Critical Review of Periodic Health 
and their apphicability is largely independent of unique patient characteristics. If a patient is in ill health, screening tests can simply be delayed until they would be better tolerated. Similarly, screening tests virtually never affect the results of other tests. Thus, because the validity of screening test guidelines tends to be relatively independent of the factual idiosyncrasies of individual cases, screening test guidelines are easier to assinilate to a general standard of care, cognizable at law, tlian are diagnostic guidelines.

Legitinuate debate occurs among practitioners regarding which circuinstances indicate the need for all kinds of tests-sucli debate is a necessary part of the process used to develop generally accepted standards ${ }^{47}$-but the peculiarly statistical nature of screening tests largely reinoves thein fron the individual practitioner's legitimate range of discretion. Screening test indications are inherently statistical because the likelihood of finding a positive result is very low. This follows froin the choice of a target population of asymptomatic, apparently healtliy individuals. A physician inay perform hundreds of tests before turning up a true positive result. ${ }^{48}$ Accordingly, it is unlikely that an individual physician will encounter enougli true positive tests to provide grounds for preferring one test to another, ${ }^{49}$ or for deciding not to test at all. For similar reasons, a physician's decision not to follow a recommended screening protocol on the grounds that testing, in his experience, rarely

Screening Using Specific Screening Criteria, Part I: Selected Diseases of Respiratory, Cardiovascular, and Central Nervous Systems, 2 J. FAMILy PRACTICE 29 (1975).

47. Disagreements will persist for some tests until more reliable data is generated. See, e.g., Not Everyone Agrees With New Mammographic Screening Guidelines Designed to End Confusion, 262 J. A.M.A. 1154 (1989) (noting controversy among various medical organizations over new mammographic screening guidelines established by the National Medical Roundtable). When reliable authorities disagree, guidehines may not be appropriate for judicial notice and instruction on the standard of care. See infra note 179 and accompanying text. Nevertheless, where different sets of guidelines agree in relevant part, courts should not iguore this consensus; judicial notice of the relevant part may be appropriate. See infra notes $179 \& 182$. Similarly, when the precise details of screeuing differ among various guidelines, yet authorities generally agree that screening should be conducted, differences in guideline details should not foreclose judicial notice that the standard of care is to conduct screening where a complaint alleges that no screening at all was performed. Id.

48. The exact likelihood will depend upon the prevalence of the disease in the screened population, and the sensitivity and specificity of the test. See infra notes 84-87 and accompanying text.

49. A physician may have a basis for his preferences, but his opinions will necessarily rely upon data from sources well beyond his own experience. An example would be to choose one method of screening over another based upon relative reports of sensitivity and specificity, as well as cost. Similarly, he may prefer one lab to another depending upon respective false positive rates. Analyses of such factors, however, assuming adequate data, are primarily mathematical and leave hitle room for subjective opinion. Further, analyses of costs, sensitivity, and specificity are often already incorporated into recommended screening protocols after careful evaluation by panels of experts specializing in precisely this type of policy formulation. The key point is that the success of screeniug protocols, because of their nature and desigu, depends upon large scale compliance: not upon paiustaking, individualized analysis of their appropriateness. 
yields positive results is prima facie unreasonable. ${ }^{50}$

Treatment guidelines-the third category-have qualities common to both screening protocols and diagnostic guidelines. On the one hand, choosing the proper treatment for an illness always requires consideration of circuinstances urique to the individual patient. The legitimate options available to a practitioner, lowever, are limited by the available, reliable data on the efficacy of various treatments. Some preventive treatments, such as vaccination protocols, are so well established that their application approxmiates the screening model. ${ }^{51}$ Yet for some illnesses, for example liypertension, ${ }^{52}$ the range of acceptable treatments is so wide that guidelines inust be broadly drawn or, in soine cases, must await generation of further data before they can meaningfully be crafted.

Because of the increased range of variables that must be considered, and the relative paucity of data, development of guidelines for treatnients and diagnostics will be a slower process than for screening tests. Nevertheless, considerable progress already has been made. ${ }^{53}$ As more data are obtained and new levels of consensus on what constitutes appropriate medical practice are reached, more guidelines will be promulgated. Additionally, with the ongoing acquisition of new data, guidelines in all three categories. can continually be developed, revised, and refinedyielding meaningful definitions of the appropriate range of inedical practice in specific areas. As this trend continues, courts will increasingly encounter practice guidelines in the context of inalpractice litigation.

Recoguition of the need for medical practice guidelines, however, and the trend toward their development, presents a unique problein in

50. Note again the distinction from diagnostic tests. Here, because of the selection of patients who are likely to yield a positive result-those with signs and symptoms suggesting the test should be done-a physician is much more hikely to encounter true positive results relative to the number of tests performed. Such experience may provide legitimate grounds for preferring one test over another-for example he may have found ultrasounds to be especially unreliable at his facility for technical or operator-dependent reasons-or for testing in some cases while not in others. Similarly, a given physician may have enough experience with a given modality that his individual skill makes it a much better test than it would be in other hands. The same point goes to choosing between various therapeutic options.

51. See, e.g., Immunization Practices Advisory Committee, New Recommended Schedule for Active Immunization of Normal Infants and Children, 35 MORBIDITY AND MORTALITY WEEKLY REP. 577, 578 (1986); Immunization Practices Advisory Committee, General Recommendations on Immunization, 32 MORBIDITY AND MORTALITY WEEKLY REP. 1 (1983).

52. See, e.g., Blood Pressure Report, supra note 35 (outlining broad range of acceptable treatment approaches to hypertensive patients).

53. For a compilation of over $\mathbf{7 0 0}$ practice parameters that have been promulgated to date by various medical specialty societies, voluntary associations, and public agencies, see OfFICE OF Quality Assurance, Am. Medical Ass'n, Listing of Practice Parameters, Guidelines AND Technology Assessments (Nov. 1989) [hereinafter Listing of Parameters]. See also Am. Med. News, July 7, 1989, at 15, col. 1 ("[S]ome practice parameters are already in place and arc saving money, and a system-wide set of parameters should be more or less complete in about two or three years."). 
the context of traditional malpractice litigation. Despite the convincing evidence $^{54}$ and growing consensus ${ }^{55}$ that medical practice guidelines are needed, and can greatly benefit pliysicians, individual patients, and society generally, compliance witli recommended practice guidelines may increase a physician's malpractice liability exposure under the current method for determining the legal standard of care. This dilemma poses a significant barrier to the adoption of practice guidelines by physicians. ${ }^{56}$ Physicians clearly should be encouraged to conform to practice guidelines when they liave been shown to result in better care; yet there is no better way to prevent conformity than to impose a legal standard of care that runs contrary to those guidelines. The following discussion illustrates the origin of this dilemma, and suggests how it may be resolved.

II

\section{The Medical Standard of Care at Law}

One of the principal averments that a malpractice plamtiff must sustain is that the defendant plyysician failed to meet the applicable standard of care. This standard, in general terns, requires that a physician possess the reasonable or ordinary degree of skill and learning possessed by other members of the same school or system practicing in the same or similar localities. ${ }^{57}$ Additionally, the defendant physician is required to exercise

54. See supra text accompanying notes $21-41$.

55. See supra note 1.

56. To some degree, the use of fiscal incentives may indirectly enforce the implementation of such policies. For example, if third party payors (private or governmental) refuse to pay for services billed that fall outside applicable guidelines, conformity with such guidelines practically will be mandated. In response to pressures from various medical societies, however, payors have thus far viewed practice guidelines primarily as educational tools for physicians, and as guides rather than strict formulas for reimbursement decisions. Am. Med. News, Feb. 10, 1989, at 3, col. 1. But see 17 Health Law. News Rep., July 1989, at 1 (noting Secretary of Health and Human Services Louis Sullivan's anticipation of payment derial and sanctions when individual physicians fail to follow rccommended treatments based on government studies); Am. Med. News, July 7, 1989, at 15, col. 1 (AMA officials noting that practice parameters could be used as possible justification for payment denials under Medicare). In any case, the best argument for implementing practice guidelines is that they represent optimal medical practice. Available evidence indicates that physicians will change their practice patterns when presented with relevant, authoritative information. LEADERSHIP COMMISSION REPORT, supra note 1 , at 18-19, 56-57.

57. The locality rule has now eroded in many jurisdictions, the trend being toward a national standard for board-certified specialists. See, e.g., Robbins v. Footer, 553 F.2d 123, 129-30 (D.C. Cir. 1977) (board-certified specialists held to national standard for doctors of same class and similar circumstances); Shilkret v. Annapolis Emergency Hosp. Ass'n 276 Md. 187, 193-99, 349 A.2d 245, 249-52 (1975) (physician must use standard of care in his class and of those in similar circumstances); Aasheim v. Humberger, 215 Mont. 127, 129-31, 695 P.2d 824, 826-27 (1985) (using same standard as doctors nationwide with same specialty); Orcutt v. Miller, 95 Nev. 408, 413-15, 595 P.2d 1191, 1194-95 (1979) (national standard adopted for board-certified specialists); see also AMa/Specialty Soc'y Medical liab. Project, A Proposed Alternative to the Civil Justice System for Resolving Medical LIABILITY Disputes: A Fault-Based, 
good judgment in applying these skills. ${ }^{58}$ In determining which behaviors correspond to this general rule, courts traditionally rely upon customary practice. ${ }^{59}$

Courts generally determine customary medical practice by receiving the testimony of expert witnesses. Juries are asked to choose between the testimony of competing experts by assessing their credibility. ${ }^{60}$ This method of determining the medical standard of care, however, has been criticized increasingly in recent years. ${ }^{61}$

Use of expert testimony to inform jurors about appropriate inedical practice is problematic because expert testimony may often be too complex and arcane for a jury to understand. Jurors' confusion may be amplified by the nature of the forum in which the expert inust testify; the forced translation between scientific language and legal terminology can result in a distorted picture of what constitutes proper inedical care. Experts are often frustrated by their inability to say anything beyond that permitted by counsel. ${ }^{62}$ In addition, financial incentives may cast serious

Administrative System 93-94 (1988) [hereinafter AMA Projecr] (discussing geographic variations of the rule on the standard of care).

58. See McCoid, The Care Required of Medical Practitioners, 12 VAND. L. REv. 549, 558-59 \& n.4 (1959) (citing Loudon v. Scott, 58 Mont. 645, 654, 194 P. 488, 491 (1920)).

59. Though not conclusive in principle, custom has been the traditional measurc of due care because of the purported incapacity of laymen (either judge or jury) adequately to evaluate the conduct of doctors. Id. at 608 . A typical formulation of the applicable standard can be found in Campbell v. United States, 325 F. Supp. 207, 210 (D. Fla. 1971):

A medical practitioner has the duty to apply to diagnosis and treatment of his patient the ordinary skills, means and inethods that are recognized as necessary and which are customarily followed in the particular case, according to the standard of those who arc qualified by training or experience to perform similar services in the community.

A few jurisdictions have specifically rejected the "custoin" measure of due care in favor of a "reasonably prudent practitioner in the circuinstances" standard. See, e.g., Harris v. Robert Groth, M.D., Inc., 99 Wash. 2d 438, 447, 663 P.2d 113, 117-18 (1983). Even under this standard, however, expert testinony generally remains critical to establish the standard of care. Id. at 449, $663 \mathrm{P.2d}$ at 119.

60. Two exceptions to the requirennent for expert testimony to establish the standard of carc are the coinmon knowledge exception (where negligence would be obvious to a laynan), Addison $v$. Whittenberg, 124 Ill. 2d 287, 297, 529 N.E.2d 552, 556 (1988), and the doctrine of res ipsa loquitur (where plaintiff may prove negligence by circuinstantial rather than direet evidence), W. KEETON, D. Dobbs, R. Keeton \& D. OWen, Prosser \& Keeton on The LAW of Torts $\$ 39$, at 256.57 (5th ed. 1984).

61. See, e.g., AMA Project, supra note 57, at 102-08 (describing problems with expert testimony and other rules of law going to proof of the standard of care); I. FREckelton, THE TRIAL OF THE EXPERT 4-12, 123-50 (1987) (discussing Australian law relevant to all common law systeins); M. KRAFT, Using Experts IN CiviL CASES 53 (1982) ("An attorney . . . will not necessarily seek the expert who is most qualified. Instead, he will probably choosc the expert who will best support his client's cause, and, perhaps, conceal its weaknesses.") (citation oinitted); Johnson, Phillips, Orentlicher \& Hatlie, supra note 15, at 1370-71 ("[T]he process of presenting issues to the jury through questioning of an expert is not always calculated to educate jurors on the issues.").

62. For a general discussion of these and other problems with the testimony of medical experts, see I. FrECKELTON, supra note 61, at 4-12, 123-50. 
doubt upon an expert's objectivity. ${ }^{63}$ Because of these factors, juries may be forced to choose between competing experts on the basis of qualities quite irrelevant to the content of their testimony, such as tone of voice, general appearance and overall demeanor. ${ }^{64}$ This problem is compounded when courts are lax in the credentials that they require for certification of a witness as an expert. ${ }^{65}$

These problems with expert testimony cast significant doubt on the rehability of jury verdicts based upon such testimony, ${ }^{66}$ and have occasioned numerous calls for reform. ${ }^{67}$ The growing need for and trend

63. Newspaper headlines proclaiming the booming market for expert witnesses reflect and engender skepticism of experts by the lay public. See, e.g., Expert Witnesses: Booming Business for the Specialists, N.Y. Times, July 5, 1987, at 1, col. 1; Testimony for Sale: Paid Experts Score Big in Legal Game, L.A. Times, Jan. 5, 1983, at 1, col. 1.

Most objectionable are "professional experts," many of whom advertise widely in medical and legal journals, and compete aggressively for the business of providing expert testimony. AMERICAN Medical ass'n Special Task force on Professional liab. and Ins., Professional LIABILITY IN THE '80S: REPORT 3, at 13 (1985); see also I. FRECKELTON, supra note 61, at 124-29; Saunders, We Can Close Down the "Hired Gun" Industry, MED. Econ., June 8, 1987, at 28, 28 ("hired-gun expert witnesses ... [seck] not so much ... the truth as to win the case for the side that hired them").

64. See O'Connell, supra note 15, at 125. Professor Havighurst observes:

Although it is customary in our adversary system to regard a jury trial as a "black box" the outcomes of which (on nonlegal questions) are granted a powerful presumption of legitimacy, realism compels recognition that juries are often poorly positioned to choose reliably between the well-argued, but often highly confusing, theories of the two sides' experts. As a result, they often fall back on such irrelevancies as the witnesses' demeanor and style of presentation or sympathy for the plaintiff's plight or the defendants' reputation.

C. Havighurst, Health Care Law and Policy 778 (1988).

When judges in the role of fact finder are faced with sophisticated scientific issues, unguided by impartial expert advice, the same inappropriate reliancc on "witness credibility" can occur. See Note, A Question of Competence: The Judicial Role in the Regulation of Pharmaceuticals, 103 HARV. L. REv. 773, 781 (1990) (describing nonjury trial in which judge, failing to comprehend underlying scientific issues, awarded plaintiff five million dollars in damages on basis of testimony of plaintiff's poorly qualified "experts" by paying "close attention to cach expert's demcanor and tone").

65. See Darling v. Reid, 534 So. 2d 255, 257 (Ala. 1988) (exclusion of testimony proffered by "expert" medical doctor who was not board-certified, and had never practiced medicine, was error on ground that qualifications went to credibility, not admissibility); AMA PROJECT, supra note 57, at 105 ("The failure of many courts to insist that experts have occupational experience in the field in which they testify has contributed to the disjunction between the legal standard of care and the standard expected of a reasonably competent and prudent practitioner.").

66. Expert testimony is notoriously unreliable, for example, in cases calling for psychological or psychiatric expertise. In one early study, experts in psychology were no more accurate than office secretaries in distinguishing between normal and brain-damaged individuals on a commonly employed screening test. Faust \& Ziskin, The Expert Witness in Psychology and Psychiatry, 241 SCIENCE 31, 32 (1988) (citing study by L.R. Goldberg published in 1959); see also Slobogin, Dangerousness and Expertise, 133 U. PA. L. REV. 97 (1984) (addressing the use of mental health expert testimony as evidence of the probability of antisocial behavior); Note, The Unreliability of Expert Testimony on the Typical Characteristics of Sexual Abuse Victims, 74 GEO. L.J. 429 (1985) (authored by Andrew Cohen) (contending that expert testimony on the typical characteristics of sexual abuse victims fails to meet the requirements for expert testimony under the federal rules of evidence).

67. See, e.g., LEADERSHIP COMMISSION RePORT, supra note 1, at 69 (calling for minimum 
toward developing practice guidelines creates a furtlier incentive to reform the use of expert testimony to establisli tlie standard of care. As discussed below, the case for reform is strongest in cases dealing with screening test guidelines. Even thougli most screening tests are relatively inexpensive individually, wlien implemented on a national scale the cuinulative expense can be enormous. ${ }^{68}$ This cuinulative financial impact of screening programs reinforces the importance of preventing juries froin undermining cost-effective screening recominendations.

\section{A. Expert Testimony and Screening Tests}

For reasons already discussed, ${ }^{69}$ guidelines for screening tests are much less open to debate than guidelines for diagnostic testing or treatinents. Accordingly, there is less need to seek out and defer to the opinions of individual experts in assessing whetler a screening test was appropriate, or whetlier not performing it was negligent. It therefore makes little sense to employ expert testimony, whicl at tlireshold suffers from a substantial ineasure of unrehability, to atteinpt to convince a jury liow and when sucli tests sliould be performed.

Screening policies, which liave broad implications for important societal policies, sliould be protected froin being arbitrarily undermined or overruled by juries who inay be inotivated by a variety of extraneous considerations. ${ }^{70} \mathrm{By}$ the very nature of the issue, grounds for reasonable dispute in individual cases are minimal and, as discussed below, ${ }^{71}$ prospectively establisled guidelines can serve as more reliable sources of

criteria to establish qualifications of expert witnesses); Havighurst, Altering the Applicable Standard of Care, 49 LAW \& CONTEMP. PROBS. 265, 268 n.12, 271 (1986) (observing that adversarial selection of expert witnesses is poorly suited to discovery of professional custom, and suggesting prospective contractual agreements between doctors and patients to govern expert qualifications and admissibility of testimony).

68. The cost of unnecessary blood clotting tests (PT and PTT) performed on the medical service of just one facility in 1988 was estimated at $\$ 60,948$. Erban, Kinman \& Schwartz, Routine Use of the Prothrombin and Partial Thromboplastin Times, 262 J. A.M.A. 2428, 2430 (1989). Similarly, it has been estimated that if just $25 \%$ of women in the United States aged 40 to 49 years receive annual mammograms, the total cost (in 1984 dollars) would be approximately $\$ 408$ million at the turn of the century. Not Everyone Agrees With New Mammographic Screening Guidelines Designed to End Confusion, supra note 47, at 1155 . The cost of annual cervical cancer screening of just 100,000 women from ages 20 to 70 years has been estimated at $\$ 29,471,000$. Eddy, The Frequency of Cervical Cancer Screening: Comparison of a Mathematicai Modei with Empirical Data, 60 CANCER 1117, 1121 (1987).

69. See supra notes $45-50$ and accompanying text.

70. Examples of such distractions include unreliable and confusing expert testimony and the understandable emotive impulse to compensate injured plaintiffs. Of course, preserving the integrity of screening protocols does not preclude recovery by deserving plaintiffs, but simply obliges plaintiffs to establish that their injury was negligently caused by the defendant. If negligence cannot be established absent repudiation of a prospectively established standard protocol, then the issue is sufficiently suspeet to warrant a pretrial ruling on the bearing of that protocol on the legal standard of care as a matter of law.

71. See infra text accompanying notes 112-14. 
authority on the standard of care than hired experts. As further guidelines are developed-guidelines for screening, diagnostics, and treatments-it gradually will be easier for courts to turn to reliable, objective authorities on the standard of care issue. A case example will help to illustrate this notion.

\section{B. Ornoff v. Kuhn and Kogan Chartered}

In Ornoff v. Kuhn and Kogan Chartered, ${ }^{72}$ Dr. Israel Kogan sued Lynne Ornoff for nonpayment of rendered medical services. Ornoff counterclaimed, alleging medical malpractice, charging that Kogan was negligent im failing to order a partial thromboplastin time (PTT) test $^{73}$ prior to performing upon her a diagnostic laparoscopy. ${ }^{74}$ Following the laparoscopy, Ornoff suffered from internal bleeding and ultimately required a total hysterectomy. After the bleeding was discovered, it was determined that Ornoff suffered from a previously unrecognized blood clotting abnormahty, ${ }^{75}$ which allegedly contributed to the post-operative bleeding.

Ornoff sought to introduce into evidence the following expert testimony to establish the standard of care:

[T] he partial thromboplastin time (PTT) test should be done "preoperatively in surgical procedures [in which] the body cavity or abdominal cavity is open[ed].". . Dr. Kogan "violated the standard of care required nationally by not performing a simple and inexpensive blood clotting factor screening test to determine if any problenis might exist before performing a laparoscopy." 76

Dr. Margaret Rick, an expert hired by Ornoff to render this testimony, had no training in obstetrics and gynecology, but was board certified in internal medicine and lematology. The trial court found Dr. Rick incoinpetent to testify as to the standard of care for obstetrician/gynecologists performing laparoscopies, and accordingly excluded her testinnony. The trial court then directed a verdict in favor of Dr. Kogan on the ground that Ornoff "failed to introduce evidence . . . that established the standard of care, violation of the standard, and a causal link between the viotion [sic] and the harm complamed of."77 The issue on appeal was whether Dr. Rick was qualified to testify as to the standard of care for

72. 549 A.2d 728 (D.C. 1988).

73. The partial thromboplastin time test measures the function of the intrinsic limb of the coagulation system, and tests the adequacy of certain blood clotting factors. HARRISON's PrinCIPLES OF INTERNAL MEdicine 272 (11th ed. 1987) [hereinafter HaRRISON's PRINCIPLES].

74. Laparoscopy is the visual inspection of the contents of the pelvis through a fiberoptic endoscope passed through a small incision in the abdominal wall. Various procedures may be performed by the use of instruments manipulated through the scope.

75. Factor XI deficiency. See generally HARRISON'S PRINCIPLES, supra note 73, at 1477.

76. Ornoff, 549 A.2d at 730 .

77. Id. at 731 . 
gynecologists. The court of appeals reversed, ruling that "a physician need not be a speciahist in the field of which he speaks in order to testify as an expert."78

The legal question in Ornoff was whether an interuist/hematologist could testify as an expert on the standard of care for an obstetrician/ gynecologist when the specific breach alleged was the failure to check a certain preoperative screening test for bleeding abnormalities (PTT). On similar facts today, however, the preliminary issue should be whether the standard of care determination should go to the jury at all. ${ }^{79}$ Arguably, the standard of care issue is a jury question where no reliable, authoritative guidelines have been clearly elucidated, ${ }^{80}$ or where more than one set of such guidehines exist and, in relevant part, differ ${ }^{81}$ Where such guidelines do exist, however, allowing a jury to undermine that standard is not only bad pohicy, but can lead to irrational results. An examination of the current standard of care as to preoperative PTT testing, as embodied in the recommendations of the American College of Physicians, illustrates the point. 82

It is now well established that the PTT is of no value as a preoperative screening test for patients with no chnical evidence of bleeding risk. ${ }^{83}$

78. Id. at 732 .

79. This is the question presented by a motion for summary judgment; such motions are almost invariably made during pretrial proceedings. Summary judgment motions differ from my proposal of judicial notice of practice guidelines because a court's ruling on summary judgment admits of no predictability or standardization among different courts. Thus the standard of care as to identical fact patterns might be held a triable issue in one case, but not in another. In contrast, judicial notice of national guidelines would permit consistency between different jurisdictions and fact patterns.

80. This was arguably the case in 1982, when Ornoff's cause of action originated. Although data existed prior to 1982 demonstrating the futility of preoperative PTT screening, see Clarkc \& Eisenberg, A Theoretical Assessment of the Value of the PTT as a Preoperative Screening Test in Adults, 1 MED. Decision MAKING 40, 40 (1981); Robbins \& Rose, supra note 17, at 796-97, it is not clear that a consensus had been reached in the medical community, and certainly many surgeons still checked the PTT routinely at that time. Nevertheless, the case illustrates the value and importance of judicial cognizance of practice gnidelines when courts must determine the standard of carc in cases where relevant guidelines are properly established.

81. See supra note 47 and infra notes $179 \& 182$.

82. The 1982 recommendations of the American College of Obstetricians and Gynecologists for basic preoperative laboratory screening prior to gynecologic surgery did not include PTT testing. The only tests specifieally recommended were a hemoglobin or hematocrit, and a urinalysis; all other testing was to be limited to those indicated by the patient's age and specific problem. AMERICAN COLLEGE OF OBSTETRICIANS AND GYNECOLOGISTS, STANDARDS FOR ObSTETRIC-GyNeCOLOGIC SERVICES 67 (5th ed. 1982). This raises the question of whether an adequate clinical history was taken to screen for bleeding tendency. But positing the need for this factual inquiry is quite distinet from asserting that the standard of care is always to order PTT tests preoperatively.

83. "Clinical evidence" includes the taking of a personal and a family history from the patient. Ornoff was Jewish and of Ashkenazi origin; the incidence of Factor XI deficiency is significant in this population. R. Colman, J. Hirsh, V. Marder \& E. Salzman, Hemostatsis and Thrombosis 26 (2d ed. 1987) (frequency of homozygotes between $0.1 \%$ and $0.3 \%$; heterozygotes between $5.5 \%$ and $11 \%$ ). One could argne, therefore, that the PTT should have been tested preoperatively even under current guidelines if there existed a "[p]ersonal or family history of known bleeding disorder." 
This follows from the sensitivity ${ }^{84}$ of the test and the prevalence ${ }^{85}$ of the abnormalities for which it screens. Because the prevalence of bleeding dyscrasias is so low in the population of asymptomatic mdividuals, and because the test is not perfectly reliable, ${ }^{86}$ the odds that a positive PTT test is a true positive are much less than the odds that it is a false positive. $^{87}$

In addition to this statistical flaw, the correlation between a true positive result and actual postoperative bleeding complications is poor ${ }^{88}$ This is not surprising since serious hemorrhages caused by bleeding disorders are very rare in asymptomatic patients, ${ }^{89}$ and most causes of postoperative hemorrhage are related instead to the type of procedure and the surgical technique. As a result, a preoperative PTT has essentially no predictive value for surgical bleeding $\mathrm{m}$ patients with no clinical evidence of bleeding risk. ${ }^{90}$

Suchman \& Griner, Diagnostic Uses of the Activated Partial Thromboplastin Time and Prothrombin Time, 104 ANNALS INTERNAL MED. 810, 812 (1986) (table 3) (reprinted in COMMON DiAgNostic TESTS: USE AND INTERPRETATION 157, 163 (H. Sox ed. 1987) [hereinafter COMMON DiAGNOSTIC TESTS]). The record does not reveal whether such a history was sought by Dr. Kogan, and Ornoff apparently did not contend that her family origins should place her in a category of higher suspicion for occult bleeding dyscrasias.

84. "Sensitivity" describes the likelihood of a positive test result in a person with the disease. Stated alternatively, it describes the ability of a test to detect persons with a given abnormality out of the screened population. Arithmetically, sensitivity is expressed as:

$$
\frac{T P}{T P+F N}
$$

where TP $=$ true positives (those with the abnormality and a positive test), and FN = false negatives (those with the abnormality and a negative test). See CoMMON DIAGNOSTIC TESTS, supra note 83 , at 16.

85. "Prevalence" is the frequency of the abnormality in the screened population at a given tine (for example, 1 ease per 100,000 persons).

86. Alternatively stated, false positives and false negatives occur.

87. The positive predictive value of the test (the probability that an abnormal result accurately refiects the presence of the abnormality) will vary depending upon the prevalence of the disease in the screened population. Thus the utility of the test increases by screening only individuals with a greater likelihood of having the abnormality. This principle is incorporated into the ACP guidelines by recominending preoperative screening of individuals for whom the clinical assessment (history and physieal findings) suggests a bleeding disorder. See Suchman \& Griner, supra note 83, at 812.

For an overview of the use of probability theory in evaluating diagnostic and screening tests, see Common Diagnostic TesTs, supra note 83 , at 1-17.

88. In a recent series of 994 cases, patients with abnormal PTT values were statistically no more likely to bleed postoperatively than patients with normal values. Manning, Beste, McBride \& Goldberg, An Assessment of Preoperative Coagulation Screening for Tonsillectomy and Adenoidectomy, 13 INT'L J. PED. OTORHINOLARYNGOLOGY 237, 242 (1987).

89. Suchman \& Griner, supra note 83 , at 810-11.

90. This is the position taken by the American College of Physicians in its recommended guidelines on PTT testing. This recommendation was first published in the Annals of Internal Medicine, the official publication of the American College of Physicians, in June 1986. Id. It was later published in book form, as one of a series of papers on various screening and diagnostic testing recommendations. Common DiAGnostic TESTS, supra note 83. The series was sponsored by the Medical Necessity Projeet of the Blue Cross and Blue Shield Association in cooperation with the American College of Physicians. Id. at xi-xiii. 
The procedure for determining the standard of care illustrated by Ornoff is problematic because it permits the jury to find that the PTT should be checked preoperatively in all asymptomatic patients even though virtually no useful information will be obtained, there will be no impact on outcome, and cumulative expenditures of societal resources will be substantial. ${ }^{91}$ This holding as to the standard of care is not just wrong, it is irrational. Furthermore, such a finding will significantly undermine physicians' ability confidently to rely upon and impleinent recommended practice guidelines. Lack of confidence will in turn lead to needless testing im the name of defensive medicine, ${ }^{92}$ thereby ignoring the enormous weight of available data on PTT testing and thwarting the important societal pohicies that the guidelines embody. ${ }^{93}$ In cases where estabhshed guidelines are at issue, juries therefore should be precluded from overruling such well-estabhished practice standards by relying upon the testimony of hired experts.

\section{Standard of Care by Judicial Fiat}

Under the rule illustrated by Ornoff, juries are permitted to determime, based upon hired expert testimony, a standard of care that under current practice guidelines would be both wrong and contrary to important public healtli and economic pohicies. As guidelines are increasingly promulgated, courts will be faced directly with the decision whether to permit juries independently to evaluate the legitimacy of these guidelines as setting the medical standard of care. The prospect of undermining estabhslied guidelines, however, is not limited to jury trials-the same folly can result when judges rule on the standard of care as a matter of law in the absence of reliable data.

In Helling v. Carey, ${ }^{94}$ for example, two opthalinologists were sued for failure to timely diagnose the plamtiff's glaucoma. The plaintiff had been treated by the defendants for approximately nine years for myopia and visual problems attributed to complications of contact lens use.

91. The calculated 1988 total cost for a PTT test at one center was quoted as $\$ 9.29$, Erban, Kinman \& Schwartz, supra note 68, at 2430-inexpensive by the standards of most medical testsbut the cumulative cost of large-scale screening is significant. See id. (1988 cost of needless PTT testing on one medical ward was over $\$ 60,000$ ); $c f$. Robbins \& Rose, supra note 17, at 797 (noting $\$ 10,000$ cost of screening 760 patients in 1979). It is unlikely that many patients would bc willing to pay the charge out of their own pockets when informed that they are paying for a useless screening test.

92. See Morris, Introduction to the Blue Cross and Blue Shield Association Guidelines, in COMMON DIAGNOSTIC TESTS, supra note 83, at 332 (guidelines should obviate the "perhaps unnecessary use" of procedures in defensive medicine). Indeed, recent studies show that despite the overwhelming evidence that PTT screening is wasteful, many physicians continue to order the test contrary to the recommended guidelines. Erban, Kinman \& Schwartz, supra note 68, at 2431-32.

93. See supra text accompanying notes 21-41.

94. 83 Wash. 2d 514, 519 P.2d 981 (1974). 
When the opthalmologists eventually tested the patient for glaucoma, she was thirty-two years of age, and had sustained partial loss of vision.

The trial court entered summary judgment for defendant opthalmologists, relying on uncontradicted expert testimony that "the standards of the profession for that specialty in the same or similar circumstances do not require pressure tests for glaucoma upon patients under 40 years of age." 95 The rationale for this standard of care was that the incidence of glaucoma in patients under age forty was only one in twenty-five thousand. In patients over age forty, however, the imcidence jumped to two or three percent, so the standard was to check pressures routinely from age forty onward. ${ }^{96}$

The Washington Supreme Court reversed, holding that the plaintiff was "entitled to the saine protection, as afforded persons over 40, essential for timely detection of the evidence of glaucoma where it can be arrested to avoid the grave and devastating result of the disease."97 The court based its decision upon the rationales that the test was simple to perform and "relatively inexpensive," there was no judgment factor involved, ${ }^{98}$ and "there [was] no doubt that by giving the test the evidence of glaucoma can be detected." 99

In addition, the court relied upon the implicit assumption that had the diagnosis been inade earher, the plamtiff's injury could have been prevented. ${ }^{100}$ In conclusion, the court stated: "[I]rrespective of . . . the standards of the opthalmology profession ... as a matter of law ... the reasonable standard that should have been followed ... was the timely giving of this simple, harmless pressure test . ..."101

95. Id. at $516,519 \mathrm{P} .2 \mathrm{~d}$ at 982 .

96. The testimony also indicated that the current standard of care was that testing should be done in the under-forty group if the patient's symptoms indicated that glaucoma should be suspected. Id. Helling had not developed symptoms of visual field defect (which suggested glaucomatous damage) until 30 days prior to the date of the diagnosis. Id. It is arguable, however, whether her symptoms prior to that time would have prompted a reasonably prudent practitioner to perform the pressure test. Thus, even under the standard depicted by defendant's expert testimony, plaintiff might have recovered were this factual issue sent to the jury. The court, however, adopted the broader approach of promulgating the new standard of screening all patients, even when asymptomatic.

97. Id. at 518,519 P.2d at 983 ; cf. supra note 46 (discussing generally accepted criteria for feasibility of screening tests).

98. See supra text accompanying notes $45-50$ (discussing the limited role of individual practitioners' judgment in determining the indications for screening tests).

99. Helling, 83 Wash. 2d at 518, 519 P.2d at 983. The court concluded by quoting Justice Hand's famous pronouncement in The T. J. Hooper, 60 F.2d 737 (1932): "[C]ourts must in the end say what is required; there are precautions so imperative that even their universal disregard will not excuse their omission." Id. at 747.

100. See 83 Wash. 2d at 518, 519 P.2d at 983.

101. Id. at 519,519 P.2d at 983. After the Helling decision, the Washington State Legislature enacted a statutory definition of the plaintiff's burden in a medical malpractice action for damages. 1975 WaSh. LAwS, Ist Ex. Sess., ch. $35, \S 1$ (codified as amended at Wash. Rev. CoDE ANN. 
The Helling court apparently intended its holding to proinulgate a new standard of care for glaucoina screening in the under-forty age group ${ }^{102}$ - a standard "higher" ${ }^{103}$ than the custoinary standard estabhished by the profession. ${ }^{104}$ As noted, two key justifications for inposing this higher standard were that the test was "relatively inexpensive," and that had the condition been diagnosed sooner, ${ }^{105}$ it could have been "arrested to avoid the grave and devastating result of this disease."106 Subsequent data, however, have cast considerable doubt upon both of these critical assumptions.

Despite the contention of soine cominentators that the Helling decision made good pohcy sense, ${ }^{107}$ one subsequent estimate suggested that the court grossly underestimated both the cost of large scale tonometry ${ }^{108}$ screening, and the efficacy of treatment. Indeed, the results cast

\$ 4.24.290 (West 1988)). The legislature apparently intended to overrule Helling and reestablish the pre-Helling standards of negligence: "[a] medical malpractice plaintiff [must] show that the defendant failed to exercise the degree of skill, care and learning possessed by others in the same professsion and that such failure caused damages." Report of the Washington House Committee on the Judiciary on Substitute House Bill No. 246, 44th Legislature, 1st Ex. Sess. (1975); see also Meeks v. Marks, 15 Wash. App. 571, 577 n.3, 550 P.2d 1158, 1162 n.3 (1976) (noting legislative purpose to reestablish pre-Helling standards of negligence). The Washington Supreme Court, however, subsequently interpreted the statute to be consistent with the Helling decision. See Gates v. Jensen, 92 Wash. 2d 246, 253-54, 595 P.2d 919, 924 (1979). Not until 1983 did the court adopt a standard for determining professional negligence that allows for improvement upon customary practice without reliance upon the court's own medical judgment. See Harris v. Robert C. Groth, M.D., Inc., 99 Wash. 2d 438, 448, 663 P.2d 113, 118 (1983).

102. There is some controversy over the degree to which the opinion actually influenced the subsequent behavior of opthalmologists. Compare Wiley, The Impact of Judicial Decisions On Professional Conduct: An Empirical Study, 55 S. CAL. L. REv. 345 (1982) (coneluding that Helling had only a minimal impact on glaucoma testing in Washington) with Givelber, Bowers \& Blitch, Tarasoff, Myth and Reality: An Empirical Study of Private Law in Action, 1984 WIS. L. REv. 443, 489 (disagreeing with Wiley's interpretation of his data).

103. Interestingly, the colloquial sense of "higher" standard seems to suggest "doing more." But in the context of the modern medical cost explosion, see supra note 8, doing less may sometimes be the "higher" standard from a public hcalth perspective.

104. The court relied upon hired, expert testimony to conclude that the prevailing standard was not routinely to test in the under-forty age group. That assumption, however, was inaccurate. According to a survey taken after the opinion was delivered, many opthalmologists in the state already were testing for glaucoma in this age group. See Wiley, supra note 102, at 362 (Table C). The Helling case thus further illustrates the dangers of judicial reliance upon hired experts to determine standards of practice. This reliance is particularly specious when used as the basis for fashioning a new legal standard with broad policy implications.

105. Although there was only a 30 day lapse between the onset of visual field symptoms and the date of the diagnosis, it was estimated that the patient had had the condition for ten years or longer. Helling, 83 Wash. 2d at 518, 519 P.2d at 982-83.

106. Id. at 518,519 P.2d at 983 .

107. See Schwartz \& Komesar, Damages and Deterrence: An Economic View of Medical Malpractice, 298 NEw ENG. J. MED. 1282 (1978) (arguing that application of the Learned Hand formula from the Carroll Towing case justifies the result in Helling on efficiency grounds).

108. Tonometry measures the intraocular pressure, which is abnormally elevated in patients with glaucoma. 
considerable doubt upon the utility of screening even in the over forty age group:

[T] he most commonly used drugs to treat the disease . . . are not always effective in lowering a patient's [mtraocnlar pressure] or in stopping the progression of field defects. From the available evidence it does not appear that earhier diagnosis makes a substantial difference in the patient's outcome. If all individuals over 40 years of age in a city of $1,000,000$ were screened, the total cost of finding and treating about 484 people with chronic simple glaucoma would be on the order of $\$ 4,944,866$ or about $\$ 13,000$ per patient potentially benefited. ${ }^{109}$

It would appear, then, that the court created a new standard of care that would result in substantial expenditure of societal resources with a very low probability of a favorable impact on the public liealth. The crucial flaw in Helling, however, is not simply that it got the data wrong, or misconstrued the actual standard of care among practitioners. Nor does the propriety of the lolding turn upon the data of any one study. ${ }^{110}$ The crucial error was the court's reliance on its own medical policy judgment to set a state-wide standard (and arguably, by spill-over effect, a nation-wide standard) of medical practice. Courts are neither technically nor administratively competent to develop and proinulgate sucli policies. Judges obviously lack the requisite medical expertise to identify and critically evaluate the data relevant to such decisions. Furtler, once a court makes such a pronouncement the standard is frozen, notwithstandimg the accumulation of new information, until the court is presented with a new case on pomt. ${ }^{111}$ This cumbersome process is ill-suited to the rapidly changing modern practice environment.

109. Eddy, Sanders \& Eddy, The Value of Screening for Glaucoma with Tonometry, 23 SuRV. Oph7halmology 194, 194 (1983); $c f$. U.S. Preventive Servs. Task Force, Guide to Clinical Preventive Services 124 (1989) (Prepublication Copy) ("There is insufficient evidence to recommend routine performance of tonometry by primary care plyysicians as an effective screening test for glaucoma.").

110. The acquisition of new data conceivably could justify a screening policy of the type promulgated by tlie court. But well-designed studies of the utility of early detection and treatment of glaucoma that miglit validate large scale screening only recently lave been publislied. See Epstein, Krug, Hertzmark, Remis \& Edelstein, A Long-Term Clinical Trial of Timolol Therapy Versus No Treatment in the Management of Glaucoma Suspects, 96 OPTHALMOLOGY 1460 (1989); Kass, Gordon, Hoff, Parkinson, Kolker, Hart \& Becker, Topical Timolol Administration Reduces the Incidence of Glaucomatous Damage in Ocular Hypertensive Individuals, 107 ARCHIVES INTERNAL MED. 1590 (1989).

111. Indecd, as noted above, see supra note 101, the Helling rule survived even beyond specific legislative attempts to overrule it. Eventually the Waslington Supreme Court adopted a less objectionable method tlian judicial fiat for improving upon customary practice, see Harris v. Robert C. Grotl, M.D., Inc., 99 Wasl. 2d 438, 448, 663 P.2d 113, 118 (1983), but Helling lias been limited to its own "unique facts" rather than overruled. Meeks v. Marks, 15 Wasli. App. 571, 577, 550 P.2d 1158, 1162 (1976): 


\section{III}

\section{Proposal}

In cases in which the standard of care is at issue, and guidelines propagated by an appropriate autlority exist, courts should take judicial notice of such guidelines and thereby remove the standard of care issue froin the purview of the jury. There are several reasons for adopting this recommendation. First, practice guidelines are prospectively determined. As a result, they will be much more objective and reliable than a jury's assessment of the opimion of a hired expert considering a case retrospectively.

Prospective standards inore accurately reflect the actual medical standard of care because medical decisionmaking is itself a prospective activity. Chimicians inake practice decisions prior to any certain knowledge of outcome. In contrast, retrospective evaluations by hired experts, in view of undesirable outcomes, inay often cause a jury to focus on perfect care rather than customary or reasonable care. ${ }^{112}$ Similarly, retrospective analyses, coinbined with understandable syinpatliy for injured plaintiffs, inay lead a jury wrongly to conclude that if a bad outcome that conceivably could have been avoided was not, then there inust have been substandard care.

Second, practice guidelines represent well-considered opinions of expert panels, based upon reviews of the best available data, as to how pliysicians should approach certain clinical problems. The prospective deliberations and consensus of such a panel are inucli more likely to be impartial and reliable than jury decisions based upon the testimony of individual experts paid to render an opinion after the fact.

Third, recognizing the legitimacy of practice guidelines at law notifies physicians of what the law expects of thein. ${ }^{113}$ Under the current jury/expert witness system, two cases with virtually identical facts can result in opposite findings on the standard of care. ${ }^{114}$ Giving legal force to practice guidelines would help dispel this inconsistency, and foster

112. See AMA Project, supra note 57, at 95; Tobias, Treating Malpractice: Report of the TWENTIETh CENTURy Fund TASK Force on Medical Malpractice Insurance $37-39$ (1986) (Background Paper) (illustrating how physicians may be found liable for malpractice despite their adherence to established procedure); Epstein, Medical Malpractice: Its Cause and Cure, in THE ECONOMICS OF MEDICAL MALPRACTICE 252-53 (S. Rottenberg ed. 1978) (discussing jury's freedom to make its own judgment as to the desirability of a particular practice).

113. Indeed, this expectation will likely provide an incentive of the type somc commentators have reported is necessary to encourage physician compliance with guidelines. See Lomas, Anderson, Domnick-Pierre, Vayda, Enkin \& Hannah, Do Practice Guidelines Guide Practice?, 321 NEW ENG. J. MEd. 1306 (1989).

114. This phenomenon engenders cynicism about the fairness and consistency of the tort system-cynicism inspiring such metaphors as "the litigation lottery" and "courtroom casino." See, e.g., P. Huber, Liability: The Legal Revolution aNd its Consequences 17 (1988). 
progress toward developing legal standards that inore accurately reflect actual optimal inedical practice.

A fourth reason legally to recognize practice standards is to discourage frivolous litigation. When the standard of care is clearly stated and lawyers know that courts will resist atteinpts to undermine it, a significant volume of needless discovery and expert consultation will be ehminated. Attorneys will be able more readily to assess the merits of potential clains early in the consultation process. Groundless claims can be dropped early on, and claims with merit can be settled more promptly where appropriate.

Finally, giving legal force to practice guidelines through judicial notice will further the societal goals that underlie the development of these practice standards. Perhaps most miportant, these goals include maximizing the cost-efficiency and overall quality of patient care, while decreasing wasteful, defensive medical practices and needless iatrogenic injury. Recognition of these standards at law also will encourage physicians to comply with guidelimes. Measured in numbers of cases litigated, my proposal does not purport profoundly to redesigu tort law generally because the number of cases that raise the prospect of undermining guidelines probably will be sinall. ${ }^{15}$ However, in terms of reinforcing and implementing the social policy of optimal, affordable health care delivery, the impact may be enormous-it takes only a few high profile cases to send a message of increased liability exposure to practitioners. Thus, among all of the advantages of guideline judicial notice, this policy-reinforcment effect is most significant.

And while diagnostic and treatment decisions may be more complex and entail more uncertainty than screeming decisions, the same logic applies to judicial recognition of diagnostic and treatment gnidelines. Where flexibility is necessary, as will usually be the case, guidelines will accomodate an appropriate range of behavior. Indeed, those who formulate diagnostic guidehines recognize this need and allow for the tailoring of care to the individual patient in the individual circunstances. ${ }^{16}$ Where tests are found not to be clinically useful, however, they are

115. Presentation of the possibility of the undermining of a guideline, however, is not the only occasion that should trigger judicial notice. Instead, notice should be taken whenever appropriate, relevant guidelines exist. See infra text accompanying notes 190-92. The result will be to provide the jury with reliable information about the acceptable range of practice in a given clinical setting. Within that range, legitimate standard-of-care questions still may be at issue-these questions will remain within the province of the jury, and will turn upon the specific facts of the case at bar. Admission of expert testimony will often remain relevant to this inquiry.

116. See, e.g., Am. Med. News, Aug. 18, 1989, at 62, col. 1 ("parameters must be made flexible enough to accommodate complicated medical decision-making") (reporting statement by Robert Doherty, American Society of Internal Medicine vice president for governmental affairs and public policy). 
labeled as not indicated, ${ }^{117}$ and optimal, first choice tests are similarly recommended. ${ }^{118}$ Where data are yet insufficient to make a recommendation, this too is stipulated. ${ }^{119}$

By taking notice of guidelines, courts also will provide some measure of security to physicians who conscientiously follow them since the burden to overcome the weight of medical authority is great. When guidelines are appropriately broad, however, they will not necessarily provide a cloak of immumty over physicians. Whether the physician's actions, in view of the facts, fall within the proper range of behavior provided by the guidelines still may be a legitimate jury question. ${ }^{120}$

The extent to which notice of guidelines limits the scope of the jury's role in assessing the standard of care will vary among different guidelines and different fact patterns. Regardless of this unavoidable (and appropriate) range of variability, however, judicial notice of guidelines will always help juries to some degree in making difficult technical decisions; notice will simultaneously reinforce important public policy goals.

Several issues remam, however. First, on whose authority should courts rely in taking judicial notice of practice standards? Second, by what procedure should these standards be determined? And finally, is judicial notice the most suitable procedural mechanism for giving legal force to practice guidehines; are judges more competent than juries correctly to identify applicable practice guidelines? The remainder of this Comment addresses these important issues.

117. See, e.g., Eddy, Screening for Lung Cancer, 111 ANNals INTERNal Med. 232 (1989) ("Because of the lack of evidence of benefit and because of its potential harms and costs, screening for lung cancer is not recommended."); Health and Policy Comm., Carotid Arteries, supra note 36, at 837 (digital subtraction angiography is not recommended when evaluating patients with carotid artery disease).

118. See, e.g., Health and Policy Comm., Gallbladder, supra note 34, at 754 (in most cases, ultrasound examination is the preferred initial test for evaluating the gallbladder).

119. See, e.g., Health and Policy Comm., Carotid Arteries, supra note 36, at 835 (pending results of ongoing prospective clinieal trials, decisions for or against preoperative diagnostic testing for carotid artery disease in patients with asymptomatic neck bruits must be individualized); accord Am. College of Physicians, Indications for Carotid Endarterectomy, 111 ANNALS INTERNAL MED. 675, 676 (1989) ("No general recommendations can be made regarding prophylactic carotid endarterectomy in the setting of planned coronary artery bypass surgery.").

120. Physicians whose practice falls outside the range will bear the burden of justifying their actions to the jury. This burden may be either heavy or light, depending upon the specific facts of a case. In cases where a physician's behavior is within the range, the plaintiff will bear the burden of showing why some other course of action within that range should have been done. Thus, judicial notice of guidelines will not amount to a per se rule of negligence-the negligence determination remains a separate jury question, but is appropriately limited by judicial notice of relevant guidelines as the legal standard of care. The result is that jurors will be more reliably informed, and guidelines-along with the policies that they represent-will be reinforced. 


\section{IV}

\section{The Proper Authority to Establish Practice GUIDELINES}

Most analysts agree on the need for improved quality and outcome assessinent, and the development of corresponding inedical practice guidelines. ${ }^{121}$ A variety of organizations-public, private, and combined-are actively developing such standards. ${ }^{122}$ Guidelines already have been established for a number of tests, procedures, and treatments. ${ }^{123}$ No consensus exists, however, as to which organization or coinbination of organizations should be primarily responsible for the development of practice guidelines. Some commentators have suggested the establishinent of a centralized, coordinated national policy-making body for the developinent of rational medical practice pohicies. ${ }^{124}$ This proposal has certain advantages; given the apparent need for large scale coordination of outcoine and quality assessment, this level of organiza-

121. See, e.g., Department Health \& Human Servs., Report of the Task Force on Medical Llability AND MALPRACTICE 84-99 (1987) [hereinafter HHS TASK FoRCE] (outlining efforts to manage quality of health care); LEADERSHIP COMMISSION REPORT, supra note 1, at 6-7, 55-65 (suggesting a quality improvement initiative); Donabedian, The Quality of Care: How Can It $B e$ Assessed?, 260 J. A.M.A. 1743 (1988) (outliming steps needed to assess the quality of medical care); Morris, supra note 92 (arguing that guidelines would help eliminate defensive medicine); Roper, Winkenwerder, Hackbarth \& Krakauer, supra note 32 (describing efforts to improve medical effectiveness).

122. Examples of private organizations imvolved iu such work are: the RAND Corporation; the American Medical Association (AMA) Diagnostic and Therapeutic Techuology Assessment program; the American College of Physicians (ACP) Clinical Efficacy Assessment Project; the American College of Radiology's Patterns of Care Study (supported by the National Cancer Institute); the Blue Cross and Blue Shield Association; and the Joint Commission on the Accreditation of Healthcare Organizations (JCAHO).

Public entities include: the Office of Technology Assessment (OTA); the Health Care Financing Administration (HCFA); the Health Resources and Services Administration (HRSA); the National Center for Health Services Research and Health Care Technology Assessment (NCHSR); the National Institute of Health (NIH); and the Institute of Mediciue (IOM).

Other organizations involved iu the activity of quality assessment include medical product makers, health care provider organizations, and universities. For a profile of twenty typical assessment programs, see IOM STUDX, supra note 1, at 255-489.

123. See, e.g., supra notes 33-36; see also Listing of PARAMETERs, supra note 53.

124. See, e.g., Division of Health Sciences Policy, INST. OF Medicine, supra note 32, at 11-13 (recommending establishment of a medical technology assessment consortium); OTA REPORT II, supra note 4, at 106-07; Bunker, Proposal, supra note 32, at 688 (proposing a private institute for health-care evaluation); Ellwood, Shattuck Lecture-Outcomes Management: A Technology of Patient Experience, 318 NEw ENG. J. MED. 1549, 1550 (1988) (health care system as organism "desperately in need of a central uervous system that can help it cope with the complexities of modern medicine"); Goodman, supra note 9, at 14-19; see also Lohr, Outcome Measurement: Concepts and Questions, 25 INQUIRY 37, $45-47$ (1988) (Council on Hcalth Care Technology established to create a public-private center concerned with technology assessment issues).

As noted previously, Congress recently crcated a new administrative agency that may perform this function of coordinatiug at the national level the development of outcome-oriented, costeffective health policies. See supra note 9. It remaius to be seen precisely how this new congressional mandate will be implemented. 
tion would facilitate large scale data acquisition and address the need for adequate funding of research. ${ }^{125}$ National level coordination would also eliminate the inefficiency and duplication which results when several organizations independently develop practice guidelines to cover the same range of practice. ${ }^{126}$ It would also simplify the task of both courts and pliysicians attempting to decide whicl guidelines are authoritative.

The qualities of an ideal medical policy-making body would include absolute objectivity, limitless access to essential data and necessary funding, the expertise necessary to evaluate the data, and a commitment to high quality, cost-effective medical care. Clearly, no such entity currently exists, and it is doubtful that such standards will ever be met by any policy-making body, national or otlierwise. But the lack of an ideal standard-setting autliority does not justify defaulting to the unacceptably flawed lired expert system. ${ }^{127}$

Similarly, the absence of perfect data upon wlich to base practice policies does not excuse the failure to develop any policy at all. The rule must be, as in any area of public policy, to use tlie best available data, and to access the best (most objective and reliable) available autliority. This Comment contends tliat professional medical societies are at present the most appropriate sources of judicially recognizable practice standards, and furthermore, that medical societies inust have a substantial participatory role in any central policy-1naking body that inay be establislied in tlie future.

\section{A. Medical Societies as Authorities for Practice Standards}

Professional medical societies are presently the optinal authorities for proinulgating judicially cognizable practice guidelines for several reasons. First, professional societies are the best autliority for the legal standard of care simply because they are the inost reliable and objective autliority for the medical standard of care. And because professional societies are the best sources of information on optinal care, it follows that they are best qualified to formulate practice guidelines. The autliority of medical societies on these issues is derived from several of their cliaracteristics.

First, professional medical societies are competent to develop practice standards for their specialty. An obviously essential element to the development of practice recoinmendations or guidelines is the necessary expertise in that field. Any autlioritative body inust therefore inevitably

125. See, e.g., OTA REPORT II, supra note 4, at 75, 107-08 (pointing out problem of insufficient government funding for medicai technology assessment and proposing policy changes to increase funding).

126. See, e.g., infra note 179 and accompanying text.

127. See supra notes $60-67$ and accompanying text. 
involve the medical profession directly. ${ }^{128}$ Furthermore, the guidelimes must be based upon chinical data, and clinicians collectively are the only source for gathermg that essential information. Professional societies possess the necessary teclnical expertise to develop and continually update practice guidelines. ${ }^{129}$

Moreover, medical societies are able to imfluence physicians to adopt optimal practice patterns because they have traditionally been recognized by physicians as legitimate sources of authority on proper medical practice. Indeed, physicians are trained in the principles of clinical practice accordimg to standards largely determined by professional medical societies. The authority of these societies is subsequently reinforced in a physician's professional career by the various prestigious journals published by medical societies, in which updates on the latest medical developments are regularly published (includimg newly developed practice guidehines). ${ }^{130}$ This historical status within the medical profession puts professional societies in a unique position to influence practitioners toward implementing proniulgated guidelines. ${ }^{131}$

Furthermore, medical societies are organized at the national level. This breadth of organization provides the administrative competence to disseninate standards on a national scale, through society publications and society-sponsored contmuing medical education. ${ }^{132}$ National prac-

128. Most analysts agree with the basic principle that decisions about liability must be based upon standards developed by the medical profession. Johnson, Phillips, Orentlicher \& Hatlie, supra note 15, at 1395; see also Strachan v. John F. Kennedy Mem. Hosp., 109 N.J. 523, 530, 538 A.2d 346,349 (1988) (noting that medical standards should be designed and imposed by the medical community); P. DANZON, supra note 10, at 149 ("there is no practical alternative to customary norms as the standard of due care"); Roper, Winkenwerder, Hackbarth \& Krakauer, supra note 32, at 1201 (envisioning refinements in medical practice guidelines by professional societies).

129. The critical need for constant reevaluation and frequent updating as new information becomes available makes a legislative body particularly unsuitable as a promulgator of practice standards. An administrative agency working with professional societies might, however, be a workable alternative as suggested by some commentators. See infra note 197; see also Am. Med. News, Jan. 26, 1990, at 1, col. 2 (describing new 1991 work plan for the Office of Inspector General of the Dept. of Health and Human Services that "will make the IG a player in future efforts to implement medical practice gnidelines").

130. See, e.g., references cited supra notes 34-36. A complete series of the ACP's Clinical Efficacy Assessinent Project statements may be purchased from CEAP at 4200 Pine Street, Philadelphia, Pa. 19104.

131. Indeed, medical societies are so established in the minds of professionals as the primary, legitimate source of reliable clinical authority that efforts to impose practice standards without the backing of the applicable specialty society probably would be doomed to failure. $C f$. HHS TASK FORCE, supra note 121, at 96 (quoting Journal of the American Medical Association editorial that it "would not be wise" to impose standards for patient monitoring during anesthesia if standards were not developed with involvement of anesthetic practitioners to whom they would apply, because acceptance would be low); Johnson, Phillips, Orentlicher \& Hatlie, supra note 15, at 1395 ("decisions about liability must be based on standards developed by the medical profession itself").

132. These continuing medical educational (CME) activities are in turn linked to board rccertification and license renewal requirements in most states-factors that help encourage 
tice standards are in keeping with the goal of standardization in medical training and health care access, as well as the growing expectations of courts and society. ${ }^{133}$ Similarly, medical societies are administratively capable of updating guidelimes as new knowledge is acquired, and efficiently disseminating this new information to the professional community. ${ }^{134}$

Another reason to recognize the authority of medical societies is the demonstrated commitment of organized medicine to the goals of high quality medical care. This comimitment is evidenced by the long history of formal peer review by physicians as a means to assure quality care-a system that developed largely in the absence of government requirements or imvolvement. ${ }^{135}$ The recent trend toward improving quality assessment and outcome evaluation similarly has been initiated in large part by private niedical societies, sometimes independently ${ }^{136}$ and sometimes in conjunction with other interested groups. ${ }^{137}$

Indeed, medical societies have played a principal role in developing virtually all of the practice guidelines that have been designed and widely implemented to date. ${ }^{138}$ These gnidelines tend to be accepted by practi-

physician compliance with guidelines. See, e.g., CAL. CODE REGS. tit. 16, § 1336 (1985) (setting forth CME requirements for California license to practice medicine).

133. The goal and reality, however, are not always co-extensive. Circumstances peculiar to local facilities, the individual physician's skills, and the patient's particular needs will need to be accounted for in the formulated standard of care. In these cases, courts should retain the common law locality rule. See supra note 57 and accompanying text. Because medical authorities appreciate this reality, practice guidelines will generally incorporate a measure of flexibility, especially for diagnostic testing. Such flexibility is both appropriate and necessary to allow a tailoring of medical care to the needs of individual patients and individual circumstances. See supra note 38.

134. See supra note 129.

135. HHS TASK FORCE, supra note 121, at 84. Examples of such private voluntary initiatives include the development of the system of board certification in medical specialties, which is traceable as far back as the $1860 \mathrm{~s}$, id. at 73-74, the system of advancement to fellowship status in medical societies, physician peer review as an adjunct to the granting of hospital privileges, and hospital credentialing through the Joint Commission on the Accreditation of Healthcare Organizations (JCAHO).

136. A few examples are the Clinical Efficacy Assessment Project of the American College of Physicians, see Schwartz, Ball \& Moser, supra note 30, the Committee on Professional Standards of the American College of Obstetricians and Gynecologists, see CoMmitTeE ON Professional. Standards, Standards For Obstetric-Gynecologic Services (7th ed. 1989), and the American College of Radiology's development of clinical standards, see AMERICAN COLLEGE OF Radiology, Clincal Standards of Patient Care and Professional Credentialing CRITERIA (1989). For a comprehensive listing of organizations involved in practice guidelinc development, see Listing of Parameters, supra note 53.

137. For example, the Medical Necessity Program of Blue Cross and Blue Shield Association was conducted in cooperation with several medical societies, including: the American Academy of Family Physicians; the American Academy of Pediatrics; the American College of Obstetrics and Gynecology; the American College of Physicians; the American College of Radiology; and the American College of Surgeons. IOM STUDY, supra note 1, at 311.

138. This does not include the standards and policies of local or private programs, such as HMO's or other pre-paid health plans. The efforts of such groups in the area of technology assessment and cost analysis have sometimes been very extensive and sophisticated, but the results 
tioners as authoritative, up-to-date benchmarks of quality practice. ${ }^{139}$ The guidelines may simply amount to an articulation of what is already recognized as optimal medical practice. ${ }^{140}$ In other cases they may clarify and define what the standard should be in an area where conflicting data and opinion have prevented formulation of a consensus. When data remain insufficient to warrant a consensus, well-designed guidelines specifically recognize such uncertainty, flagging it as a target for future research.

\section{B. Objections to Medical Societies as Authority}

Critics might contend that the sensitivity of medical societies to the malpractice issue makes them poorly suited to the task of setting practice guidelines. For example, medical societies might set gnidelines too broadly, so as to preclude meritorious claims, no matter how unreasonable the practice. Similarly, a given specialty may have self-interests that could bias recommended gnidelines in one direction or another. Thus, if a particular specialty profits by the frequent performance of a test, their recommendations may be biased toward performing the test more frequently than the data might indicate.

These objections are reasonable, but not conclusive. Clearly, no single orgamization will ever be purely objective. Third-party payors are tainted by fiscal bias, and federal and state governments are subject to the same criticism as underwriters for a substantial portion of the national health bill. Corporations engaged in quality assessment are profit-naking enterprises, ${ }^{141}$ as are the medical supply and pharmaceutical industries.

Therefore, to argue that imperfect objectivity is a fatal flaw is to prove too inuch-by that standard, courts could never find an acceptable authority on the standard of care. But again, the present lack of an ideal entity does not preclude the development of needed guidelines by the most appropriate available authority. ${ }^{142}$ In addition, to the extent that

generally are not formulated as practice guidelines. Instead, findings are used as the basis for informed management decisions. See, e.g., id. at 343-46 (describing the technology assessment activities of the Division of Health Services Research of The Permanente Medical Group, Inc.).

139. See, e.g., HHS TASK FORCE, supra note 121, at 96 (discussing physician acceptance of standards for patient monitoring during anesthesia; the general goal of the standards was desirable, many physicians were already conducting themselves in accordance therewith, and there was potential for reducing malpractice premiums and claims).

140. See id.

141. Even "nonprofit" corporations have profit-related motivations. See Horwitz, Corporate Reorganization: The Last Gasp or Last Clear Chance for The Tax-Exempt, Nonprofit Hospital?, 13 AM. J.L. \& MED. 527, 533 n.36 (1988) (citmg secondary gains such as greater prestige within the institution or community, creation of a larger organization, and salary increases for administrators).

142. Nor does the future possibility of a balanced, central policy-making body-for example an institute composed of several interested factions, both public and private-preclude courts from 
such guidelines are developed in cooperation with organizations whose own interests counterbalance the self-interests of the medical society, this objection is diluted. ${ }^{143}$

Further, where guidelines are too vague and overbroad-whether by design or perforce due to a paucity of data-malpractice claims will not be thwarted. Instead, such guidelines will simply be inapplicable to a specific pleaded cause of action. Courts will not be expected to invoke irrelevant guidelines as the standard of care. On the other hand, the same interests that initially inotivate medical societies to develop practice guidelines ${ }^{144}$ will encourage them to desigu standards that are as specific, and therefore as useful, as the available data permit.

Furtliermore, altliough inedical societies may be inotivated in part by a desire to minimize malpractice litigation, ${ }^{145}$ this motive is not necessarily objectionable if the means of avoidance is reducing avoidable medical mjury by designing guidelines that eliminate substandard care. This is exactly the kind of deterrence that, according to its proponents, the tort system is designed to engender. ${ }^{146}$

Finally, notice of practice guidehines imay actually raise the standard of care in some cases by changing the standard from what doctors custoinarily do to what doctors ought to do. ${ }^{147}$ It is difficult to see how this would disadvantage plaimtiffs witl meritorious claims.

Therefore, while there are drawbacks to medical societies being the exclusive promulgators of practice standards, the advantages distinctly outweigh the disadvantages. Moreover, the disadvantages are traceable to the observation that inedical societies are not perfectly objective on issues of malpractice risk or financial welfare-defects that are substan-

deferring to the best available authorities now. Indeed, a willingness of courts to give legal force to guidelines promulgated by the current best source of medical authority would instill further incentive in non-medical groups to lobby for establishment of a policy making body that would more closely approximate this ideal of balanced objectivity.

143. See supra note 137.

144. These motivations include a commitment to high-quality, efficient, and cost-effective medicine. IOM STUDY, supra note 1, at 276 (quoting the central purpose of the Clinical Efficacy Assessment Project); see also text accompanying note 151. Another ineentivc for guideline designers to be accountable to nonmedical interests, and to produce workable practicc standards, is the political reality that if practice guidelines fail in their mission to optimize and economize medical care, political contraints objectionable to medical organizations may be implemented instead. See, e.g., Am. Med. News, July 7, 1989, at 15, col. 1 (describing AMA's endorsement of practice guidelines as a cost-saving alternative to expenditure targets); Am. Med. News, Aug. 18, 1989, col. 1 at 62 (Congress will not view practice parameters as a serious alternative to expenditure targets unless they have some "teeth").

145. See HHS TASK FORCE, supra note 121, at 96.

146. See, e.g., Teret \& Jacobs, Prevention and Torts: The Role of Litigation in Injury Control, 17 LAW, MED. \& HeAlTH CARE 17, 20-21 (1989). Many critics argue that the present tort system fails miserably in its deterrent function. See, e.g., Johnson, Phillips, Orentlicher \& Hatlie, supra note 15, at 1371-73; Sugarman, Doing Away With Tort Law, 73 CAL1F. L. Rev. 555, 564-73 (1985).

147. See infra text accoinpanying notes 183-86. 
tially ameliorated by joint participation with organizations whose interests have a counterbalancing effect. Such joint participation is already incorporated in some cases, ${ }^{148}$ and the trend seems to be in this direction generally. ${ }^{149}$ Nevertheless, whatever final form a policy-making body assumes-governmentally sanctioned or otherwise-the qualities and abilities of professional inedical societies make them essential key players in the authoritative formulation and promulgation of practice guidelines.

$\mathrm{V}$

Critique of the Methodology Used to Develop Practice Guidelines

The defensibility of judicial deference to medical practice guidelines on the standard of care issue depends upon the reliability and integrity with which those standards are derived. Thus, we must evaluate the methodology used by medical organizations to establish practice standards. This evaluation requires both a consideration of the specific methods used to generate practice gnidelines and an analysis of the cognitive underpinnings of clinical reasoning generally-cognitive assumptions which may differ substantially from those of traditional legal premises.

\section{A. Methodology of Practice Guideline Development}

Practice guidelines depend substantially upon assessments of relevant medical technologies. The precise methods used to evaluate a given technology are determined by the purpose of the orgamization conducting the evaluation. For example, a corporation may engage in technology assessment of products it plans to manufacture. To this end the corporation may conduct its own clinical trials, laboratory testing, cost analyses, and other studies. ${ }^{150}$

The Clinical Efficacy Assessment Project (CEAP) of the American College of Physicians (ACP) exemplifies one medical society's effort to promulgate practice guidelines. The stated purpose of the CEAP is "to help physicians practice high-quahity, more-efficient, and cost-effective medicine."151 To this end, the ACP primarily uses a combination of group judgment, expert opinion, and hiterature syntheses to assess the efficacy of relevant technology. The ineinbers who govern CEAP are skilled in medicine, clinical epidemiology, statistics, decision analysis,

148. See supra note 137.

149. See, e.g., Bunker, Proposal, supra note 32, at 688 (asserting that proposed private institute for health-care evaluation "must be governed through a system of checks and balances by constituent groups" in order to maintain credibility).

150. For a detailed discussion of the technology assessment programs of various organizations, see IOM STUDY, supra note 1, at $255-489$ (profiles of 20 technology assessment programs).

151. Id. at 276 . 
technology assessment, economics, and public policy. ${ }^{152}$ Outside expert opinions are also sought and considered in the evaluation process. ${ }^{153}$

This methodology has several advantages. The review and synthesis of medical literature crystallizes the available information on a given topic, permitting comprehensive analysis. Further, areas in which insufficient data are available are identified, and guidelines can be formulated to reflect this uncertainty and call attention to the need for further research. Additionally, this method closely approximates the traditional process of consensus building which characterizes the development of those beliefs and practice conventions that constitute accepted medical practice. This aspect of the method lends a quality of authenticity to the process because the experts are functioning within their traditionally recognized realm of expertise. Accordingly, physicians and courts alike will feel more justified in deferring to a committee's recommendations.

Of course, the notion that courts ought to defer to what the nedical profession deems to be good practice is far front controversial; this is the very rationale behind hearing expert medical testimony-to discover what standards physicians have set for acceptable practice. The innovative aspect of practice guidelines is that now, where available data pernit formulation of guidelines, standards of care can be clearly and prospectively articulated by medical authorities whose expertise and objectivity compare favorably to that of expert witnesses hired after the fact.

Thus, the CEAP practice guideline developnent process comiports with the range of activities and subject matter traditionally considered to be within the expertise of medical professionals. The credibility of the resulting guidelines is therefore reinforced by the inethodology used to develop then.

However, the non-traditional technique of using cost-effectiveness analysis to assess medical care dehivery is appearing in the professional literature with increasing frequency. ${ }^{154}$ This method likely will become

152. Id. at 278 .

153. Where consensus or reasonable certainty cannot be achieved, guidelines can be designed with enough flexibility to accommodate "respectable minority" views. False consensus is guarded against by the process of seeking outside expert opinion, so that in the end, guidelines are an accurate reflection of optimal medical practice as determined by currently available data and practice conditions. For a complete description of the evaluation process, see id. at 277-78.

154. See, e.g., Cummings, The Cost-effectiveness of Convincing Smokers to Quit, 261 J. A.M.A. 75 (1989) (cost of routine, brief advice about smoking cessation by physicians ranged from $\$ 705$ to $\$ 988$ per year of life saved for men and from $\$ 1204$ to $\$ 2050$ for women); Kinosian \& Eisenberg, Cutting Into Cholesterol: Cost-effective Alternatives for Treating Hypercholesterolemia, 259 J. A.M.A. 2249 (1988) (cost of reducing serum cholesterol levels with cholestyramine was $\$ 59,000$ per year of life saved compared to treatment with oat bran at $\$ 17,800)$; Weinstein, Cost-effectiveness of Interventions to Prevent or Treat Coronary Heart Disease, 6 ANN. REv. PuB. HeALTH 41 (1985) (cost of reducing diastolic blood pressure from 110 to $90 \mathrm{mmHg}$ in 1974 dollars was $\$ 16,330$ per year of healthy life saved for a 60 -year-old man). 
an additional factor to be considered by nedical organizations in developing guidelines. ${ }^{155}$ Appraisal of the cost-effectiveness of a medical test or procedure, while routinely considered by inany technology assessnient organizations, is not within the traditional scope of medical expertise. Because cost-effectiveness analysis is a tool relatively new to the niedical sciences, its use by medical authorities in developing practice guidelines deserves particular attention.

\section{B. Cost-effectiveness Analysis in Practice Guideline Development}

Although formal cost-effectiveness analysis is new to practice guideline development, guidehines have always promoted more efficient utilization of services. Practice guidelines directly and imtentionally promote cost-effectiveness by encouraging appropriate utilization of services and discouraging expensive practice patterns that correlate poorly with favorable outcoines. Nevertheless, formal cost-effectiveness analysis is a "nonmedical" policy-nraking function, that entails deciding which medical practices and procedures are "worth" nore to society.

On its face, this characterization sounds suspect. After all, medical experts seem to have no special training or authority that qualifies them to place a dollar value on huinan life or health. On close inspection, however, the use of cost-effectiveness analysis by chinicians is much less objectionable than it may initially appear. First, this type of analysis is quickly becoming a well-established contponent of climical reasoning. Thus the assertion that cost-effectiveness analysis is beyond the range of "medical" expertise is no longer accurate. Instead, expertise im this field is now analogous to expertise in epideiniology, decision analysis, and other sophisticated statistical tecliniques-fields already frequented by medical and public health subspecialists.

Furthermore, cost-effectiveness analysis does not require an extreme degree of subjectivity, as is cominonly perceived. In this regard, costeffectiveness analysis must be distinguished from cost-benefit analysis; though related, these two metlods of health practice assessnient are distinguishable. While cost-benefit analysis must value all outcoines in econoinic (dollar) terms, cost-effectiveness analysis places priorities on alternative expenditures without assessing a dollar value on life and health. ${ }^{156}$ Cost-effectiveness analysis entails the seemingly uncontroversial assumption that society wishes to maximize the total aggregate health benefits conferred, given the operative budgetary constraints. Costs are measured in dollars, but liealth effectiveness is expressed in

155. See, e.g., Gifford, 1988 Joint National Committee Guidelines for Managing Hypertension: How Are They Different?, 56 Cleveland CliniCal J. MED. 41, 46 (1989) ("For the first time, the JNC addresses the issue of cost of antihypertensive therapy . ...").

156. Weinstein \& Stason, supra note 5, at 717. 
terms of quality-adjusted life years (QALYs). ${ }^{157}$ The ratio of costs to benefits, expressed as cost per quality-adjusted year of life saved, becomes the cost-effectiveness measure, and this value is ranked against competing medical practices and technologies assigned similar values. ${ }^{158}$ The point on the ranked hist where society is no longer willing to pay the cost of the benefits achieved becomes society's cutoff level of permissible cost per unit effectiveness. ${ }^{159}$

Of course, both cost-effectiveness analysis and cost-benefit analysis suffer the limitation that benefits and costs to individual members of society must be aggregated. But this condition cliaracterizes any attempt to address social policy questions at the macroeconomic level. Thus, an attempt to redress this imperfection would result in replacing an imperfect conceptual framework with no framework at all. It is precisely this lack of a centralized, macroeconomic approacli to quality control that has led to current levels of fiscal inefficiency and inadequate outcome

157. The advantage of this unit is that it incorporates changes in both survival and morbidity in a single ineasure that reflects tradeoffs between them. Id. Unavoidably, there remains a subjective component, since it is the human experience of health and well-being that is being quantified. See infra note 158.' In addition, future costs and health benefits must be discounted, preferably for a range of discount rates. Weinstein \& Stason, supra note 5, at 719-20.

158. The net health-care costs $(\Delta C)$ of a program or medical practice may be calculated (in dollars) according to the following formula:

$$
\Delta \mathrm{C}=\Delta \mathrm{C}_{\mathrm{Rx}}+\Delta \mathrm{C}_{\mathrm{SE}}-\Delta \mathrm{C}_{\mathrm{Mort}}+\Delta \mathrm{C}_{\mathrm{R} x \Delta \mathrm{LE}}
$$

where $\Delta C_{R x}$ includes all direct medical and health care costs (hospitalization, physician time, medications, laboratory services, counseling and other ancillary services); $\Delta \mathrm{C}_{\mathrm{SE}}$ includes all health care costs associated with the adverse effects of treatment; $\Delta C_{\text {Morb }}$ refers to savings in health care, rehabilitation and custodial care costs due to prevention or alleviation of disease; and $\Delta \mathrm{C}_{\mathrm{R} \times \Delta \mathrm{LE}}$ includes the costs of treating diseases that would not have occurred if the patient's life had not been prolonged by treatment.

Similarly, the net health effectiveness of a program or medical practice unay be calculated (in QALYs) as:

$$
\Delta \mathrm{E}=\Delta \mathrm{Y}+\Delta \mathrm{Y}_{\mathrm{Morb}}-\Delta \mathrm{Y}_{\mathrm{SE}}
$$

where $\Delta E$ is the expected number of quality-adjusted life years; $\Delta Y$ is the expected number of unadjusted life years; $\Delta Y_{\text {Morb }}$ represents improveinents in the quality of life years due to the alleviation or prevention of morbidity; and $\Delta Y_{S E}$ represents decreases in the quality of life years due to the side effects of treatment.

While the QALY quantity avoids the objection of measuring quality of life in terms of dollars, the assignment of a value is of course ultimately and unavoidably subjective. The value assigned, according to Weinstein \& Stason, can be thought of as reflecting answers to questions like the following:

Taking into account your age, pain and suffering, inınobility, and lost earnings, what fraction, $P$, of a year of life would you be willing to give up to be coinpletely healthy for the remaining fraction of a year instead of your present level of health status for the full year?' Or 'Taking into account these same factors, what probability, $\mathrm{P}$, of death would you be willing to accept so that, if you survived, you would have full health rather than you present health status for the rest of your life?

Weinstein \& Stason, supra note 5, at 719. To allow for the fact that different individuals would answer these questions differently, a societal-level cost-effectiveness analysis uses a range of possible weights to reflect the spectruin of individual values. Id.

159. Id. at 717 . 
assessment. $^{160}$

Despite this defense of cost-effectiveness analysis by medical experts in developing practice guidelines, the valid criticism remains that there is considerable subjectivity and uncertainty in the calculation of the effectiveness ratio. These limitations, however, are not entirely without redress. Sensitivity analysis can be used to test whether basic conclusions change as individual variables are valued over the range of uncertainty. Where marked differences in outcome result from varying uncertain terms, further studies can be focused to help limit the level of uncertainty for those terms. ${ }^{161}$

This remedy, while imperfect, illustrates one of the primary virtues of cost-effectiveness analysis. The analytic process, as one facet of the guideline-developinent process, forces the articulation of beliefs and values that underlie difficult allocation decisions that must eventually be made. ${ }^{162}$ The choice is to make them with the help of a systematic, responsible analysis or no analysis at all.

\section{Negligence and Probabilistic Causation in Clinical Decisionmaking}

Aside from the metlodological considerations discussed above, certain epistemological differences between judicial and clinical decisioninaking must be addressed at the policy level. The coinmon law traditionally employs the notion of "proximate cause" when evaluating the relationship between defendants' actions and plaintiff' injuries. Precisely what is entailed by this concept has been the topic of substantial scholarly debate, and a full discussion is beyond the scope of this Cominent. ${ }^{163}$ It is sufficient here to observe that the legal concept of causation is quintessentially retrospective. Judicial decisions about causation and resultimg liability are always made in liglit of, indeed because of, the occurrence of an injury. In contrast, clinical decisionmaking always occurs in the context of risk, or a given probability of injury depending

160. See supra notes $2-9$ \& $26-35$ and accompanying text.

161. Sensitivity analysis quantifies the level of uncertainty of basic conclusions by varying, one at a time, the most uncertain features and assumptions in the cost-effectiveness calculation over the range of possible values. If the basic conclusions do not change when a particular feature or assumption is varied, confidence in the conclusion is high. If the basic conclusions are sensitive to variations in the tested assumption, confidence is lowered, and the assumption is targeted for further research. Weinstein \& Stason, supra note 5, at 720-21.

162. Cf. OTA REPORT II, supra note 4, at 60 ("The value of CEA lies more in the process of performing the analysis than in any numerical results.").

163. For a terse discussion of the theoretical underpinnings of proximate or legal causation as compared to the modern scientific notion of causation, see Brennan, Untangling Causation Issues in Law and Medicine: Hazardous Substance Litigation, 107 ANNALS INTERNAL MED. 741 (1987); Brennan \& Carter, Legal and Scientific Probability of Causation of Cancer and Other Environmental Disease in Individuals, 10 J. Health Pol., PoL'y \& L. 33 (1985). 
upon alternative courses of action-it is a prospective enterprise, ${ }^{164}$ the goals being to maximize health and ininimize the likelihood of illness (or "injury") to individuals.

This distinction inay not seem problematic when considering the actions of individual physicians and plaintiffs. When finding negligence and culpability, the court simply recognizes that the physician miscalculated the risk of injury-she should have known that her decision would have increased the likehliood of injury to an unacceptable level in view of other options. When this miscalculation results in (proximately causes) injury, slee is liable in tort and plaintiff is therefore entitled to compensation.

But the "proximate" model of causation does not as readily fit when applied to injuries that have occurred in the context of screening protocols or the implementation of otlier practice gnidelines. Screening guidelines aptly illustrate the point; the very notion of a screening protocol assumes an incidence of disease that is certain to occur. Indeed, it is precisely this certainty of future "injury" that occasions the use of a screening test in the first place-the goal is to minimize inorbidity and mortality by making timely diagnoses of predicted diseases, that is, when preemptive intervention can be made. ${ }^{165}$ The tradeoffs against universal prevention are cost and convenience; at some point society inust inake a policy decision regarding how mucl expense and inconvenience it is willing to bear to address a given risk of disease. Once that policy choice is made, regardless of where the line is drawn, there will always remain a certain incidence of disease.

The certainty of disease ${ }^{166}$ persists even if the screening protocol is ideally implemented. This incidence is inevitable because screening tests are not foolproof, either in their technical aspects or their design. There will always be false positive results (causing needless further investigation), false negative results (causing failure to diagnose), and cases for which the chosen testing interval is too long (causing failure to diagnose in time to avert morbidity or mortality).

The inconsistency arises when these predictable cases are realized, and the unfortunate patient-now plaintiff-develops disease despite conscientious application of the screening protocol. From the medical or epidemiological point of view, the case is straightforward: this is one of the cases that was predicted to occur, given the interval of testing and the

164. Cf. Johnson, Phillips, Orentlicher \& Hatlie, supra note 15 , at 1396 (suggesting redefining the rules of causation to more accurately reflect the probabilistic nature of medicine and medical injuries).

165. See supra note 46.

166. That is, disease that will not be diagnosed early enough in its course to prevent substantial morbidity or mortality. 
limitations of the test chosen. The event is simply an instantiation of the prior known risk.

In the courtroom, however, this statistical certainty that has been accepted at the policy level and integrated into a screening program inay translate into personal hability for physicians implementing that policy. Juries focus retrospectively on the individual plaintiff before them who allegedly has been "injured." Retrospectively, the relevant legal question is reformulated to focus on the imdividual-could anything have been done to prevent this unfortunate individual from being injured? Could the screening test have been performed more frequently? Could another test have been done that might have led to a more timely diagnosis in this case?

The answers to these questions will often be yes. But juries are not required to consider these questions from the prospective point of view in which injured individuals cannot be identified ex ante. Indeed, jurors are instructed in the legal, proximate formula for causation, not the scientific, probabihistic definition. ${ }^{167}$ Nor does the jury consider the societal burdens of cost, convenience, and test-related morbidity of alternative testing protocols; it need not consider that other testing parameters suggested by plaintiff would have to have been impleinented on a massive scale to have prevented plaintiff's injury. Instead, the jury focuses on the injured individual, and no currently enforced legal principle precludes its finding that the failure to use a different screening protocol or test "proximately caused" the plaintiff's injury, and that compensation is therefore due. ${ }^{168}$

The problein with this process is that juries are performing a function which they are neither called upon nor qualified to perform. Under the auspices of addressing individual complaints, juries are reassessing and reformulating on an ad hoc basis all of the pohicies and medical evidence underlying the developinent of screening programs. The saine logic applies to established diagnostic or treatment guidelines-carefully considered policy choices designed to serve society's best interests, and based on the best available data, will be directly undermined if juries are permitted to overrule or ignore these guidehines in individual cases. Froin the defendant's point of view this is simply unfair, and from a societal point of view, it is siniply bad policy.

167. See, e.g., 1 Comm. ON Standard Jury Instructions, Civil, California Jury INSTRUCTIONS CIVIL $\S \S 3.75-3.76$ (C. Loring ed. 1986) (suggested jury instructions for "proximate cause" and "legal cause").

168. This situation is distinguished from a case in which screening protocols are negligently implemented-a very different case. There the effect is to reinforce the social policies underlying proper screening for disease, not to undermine them. 
VI

\section{Use of Judicial Notice to Give Legal Force to PRACTICE GuIDELINES}

Judicial notice is the acceptance of the truth of certain facts without requiring the introduction of evidence by the party who ordinarily would have the burden of producing such evidence. ${ }^{169}$ The two primary goals of judicial notice are the promotion of trial expedience and the prevention of flagrant error. ${ }^{170}$ The Federal Rules of Evidence regulate judicial notice of adjudicative facts, ${ }^{171}$ and virtually every state has analogous provisions for state proceedings. ${ }^{172}$ The proposal that judges take judicial notice of relevant medical practice guidelines when adjudicating

169. 9 J. W1GMORE, EvidENCE § 2567(a), at 716 (4th ed. 1981).

170. Comment, Judicial Notice: Rule 201 of the Federal Rules of Evidence, 28 U. FLA. L. REV. 723, 724 (1976) (authored by Carla A. Neeley).

171. FED. R. Evid. 201. The rule in full reads as follows:

(a) Scope of rule. This rule governs only judicial notice of adjudicative facts.

(b) Kinds of facts. A judicially noticed fact must be one not subject to reasonable dispute in that it is either (1) generally known within the territorial jurisdiction of the trial court or (2) capable of accurate and ready determination by resort to sources whose accuracy cannot reasonably be questioned.

(c) When discretionary. A court may take judicial notice, whether requested or not.

(d) When mandatory. A court shall take judicial notice if requested by a party and supplied with the necessary information.

(e) Opportunity to be heard. A party is entitled upon timely request to an opportunity to be heard as to the propriety of taking judicial notice and the tenor of the matter noticed. In the absence of prior notification, the request may be made after judicial notice has been taken.

(f) Time of taking noticc. Judicial notice may be taken at any stage of the proceeding.

(g) Instructing jury. In a civil action or procceding, the court shall instruct the jury to accept as conclusive any fact judicially noticed. In a criminal case, the court shall instruct the jury that it may, but is not required to, aceept as conclusive any fact judicially noticed.

The advisory committee's note defines adjudicative facts as "simply the facts of the particular case," as opposed to legislative facts, which are "those which have relevance to legal reasoning and the lawmaking process, whether in the formulation of a legal principle or ruling by a judge or court or in the enactment of a legislative body." FED. R. EvID. 201 advisory committee's note, subdivision (a). Cf. Davis, An Approach to Problems of Evidence in the Administrative Process, 55 HARv. L. REv. 364, 404-07 (1942) (coining the adjudicative/legislative fact terminology).

The following discussion assumes that practice guidelines fall into the category of legislative facts in jurisdictions where the distinction is relevant. Judicial notice of legislative facts apparently is permitted in federal proceedings; it is not, however, regulated by the Rules. See FED. R. EvID. 201 advisory committee's note, subdivision (a) (describing the importance of judicial freedom to think about the factual ingredients of what the law ought to be for the process of judge-made law to grow, thus making strict regulation of notice of legislative facts inappropriate); see also Annotation, What Constitutes "Adjudicative Facts" Within Meaning of Rule 201 of Federal Rules of Evidence, Concerning Judicial Notice of Adjudicative Facts, 35 A.L.R. FED. 440, 444 (1977) (citing Professor Cleary, reporter for the advisory committee on the Federal Rules of Evidence, in Fonvard, Symposium on Proposed Federal Rules of Evidence, 1969 LAW \& Soc. ORD. 509).

172. See, e.g., CAL. Evid. Code $\S \S 450-460$ (West 1988). The California Code, and the majority of states which have not adopted the federal rule, do not distinguish between adjudicativc and legislative facts. 
medical malpractice cases requires a brief consideration of the admissibility of scientific evidence generally.

\section{A. Scientific Evidence in the Courts-The Frye Standard}

Admission of scientific evidence generally requires expert testimony, primarily to assist the jury in understanding the subject matter at issue. Medical evidence is no exception to this rule. Many courts, however, impose the additional requirement that the offered scientific test or principle must be "generally accepted" by the scientific commurity. This special requirement for the admissibility of scientific evidence derives from Frye v. United States. ${ }^{173}$ The Frye rule lias been unevenly applied in different jurisdictions, and rejected in sonne. ${ }^{174}$ While its current legal status does not control the thesis of this Comment, ${ }^{175}$ consideration of the Frye rule nevertheless helps illustrate the advantages of judicial notice of practice guidelines.

Frye was concerned primarily with the threshold question of the admissibility of scientific evidence; a jury inay, of course, give little or no weiglit to that evidence once admitted. My proposal, however, is not simiply that practice guidelines be admitted, but that judicial notice and mstruction remove the standard of care issue from the jury in cases where applicable guidetines have been promulgated. As discussed below, this proposal avoids many of the procedural problems which have led some courts to reject Frye.

\section{B. Procedural Advantages of Judicial Notice-Analogy to Frye}

Decisions whether to admit scientific evidence and whether to take judicial notice of practice guidelines involve many of the same procedural considerations. Initially, the existence of sucli guidelines, and the fields to which they apply, must be indentified by the court. Under Frye, the court's attention to proffered evidence is drawn by adversarial counsel. While this remains an alternative under the guidelme notice proposal, a

173. 293 F. 1013 (D.C. Cir. 1923). Frye involved tlie use of a lie detector test (polygraph) by tlie defendant in a murder case. The appellate court affirmed tlie lower court's refusal to admit the evidence, reasoning tliat, "while courts will go a long way in admitting expert testimony deduced from a well-recognized scientific principle or discovery, the thing from which the deduction is made must be sufficiently established to have gained general acceptance in tle particular field in which it belongs." Id. at 1014.

174. See, e.g., Harper v. State, 249 Ga. 519, 525, 292 S.E.2d 389, 395 (1982) (rejecting the Frye admissibility standard of general aceeptance in the scientific community in favor of "whetler the procedure or teclinique in question has reached a scientific stage of verifiable certainty"). For a general discussion of the Frye standard, see Note, The Frye Doctrine and Relevancy Approach Controversy: An Empirical Evaluation, 74 GEo. L.J. 1769 (1986) (autliored by Steven M. Egesđal).

175. Indeed, Frye has not traditionally been applied to medical evidence or medical expert testimony in malpractice cases. Black, $A$ Unified Theory of Scientific Evidence, 56 FordHAM L. REV. 595, 647 (1986). 
superior procedure would be judicial retainer of impartial experts. ${ }^{176}$ Court-appointed experts could inform the court of existing, relevant practice guidelines appropriate for the defendant physician's specialty or sub-specialty.

While determining the appropriate field of application was problematic under Frye, ${ }^{177}$ here that determination is made automatically. The guidelines simply apply to those physicians practicing within the specialty for which the guidehines were devised. ${ }^{178}$ In cases where two sets of apphicable standards conflict, ${ }^{179}$ however, the lack of consensus would preclude the court from adopting either as the standard of care at law.

Once the court identifies an applicable guideline, the Frye model requires it to determine whether it has been generally accepted. ${ }^{180}$ While this task may be problematic for novel scientific evidence, it is less so for practice guidelines. That guidelines have been estabhshed by qualified medical authorities provides compelling evidence of general (though not necessarily umiversal ${ }^{181}$ ) acceptance. To dispel this inference requires a similar weight of authority with comparable objectivity and reliability, such as the contrary recommendation of another medical specialty. ${ }^{182}$

176. This option is already provided to federal courts. See FED. R. Evid. 706. Most states have analogous provisions. See, e.g., CAL. Evid. CodE $\S 730$ (West 1988).

177. Gianneili, The Admissibility of Novel Scientific Evidence: Frye v. United States, a HalfCentury Later, 80 CoLUM. L. REv. 1197, 1208 (1980).

178. It should be held incumbent upon the physician to be familiar with the standards set for the specialty under which she practices, regardless of her formal training-if a physieian holds herself out as an expert, the state should hold her to standards applieable to other experts in the same field.

179. For example, suppose a gynecologist/oncologist screened patients of a certain age every 3 years for cervical cancer in accordance with the guidelines recommended by the American Cancer Society (ACS). Am. Cancer Soc'y, Survey of Physicians' Attitudes and Practices in Early Cancer Detection, 35 CA-A CANCER J. For Cliniclans 197, 199 (1985). A patient who subsequently develops cervical carcinoma two years after her negative screening test eharges malpractice for failure to diagnose, citing the guidelines set by the American College of Obstetricians and Gynecologists (ACOG) which recommend yearly screening. COMM. ON Professional STANDARDS, STANDARDS FOR OBSTETRIC-GyNECOLOGIC SERVICES 55 (6th ed. 1985). Note, however, that this lack of consensus on the partieulars of how often to screen may be no defense where a physician with an appropriate duty fails to perform any screening at all. This is because there is a consensus that screening at some frequency should be done. See infra note 182. (This hypothetical would apply only to a cause of action arising prior to 1988 because ACS and ACOG since have reached a consensus on a recommended screening interval for cervical cancer. See Fink, Change in American Cancer Society Checkup Guidelines for Detection of Cervical Cancer, 38 CA-A CANCER J. For Clinicians 127, 128 (1988)).

180. Giannelli, supra note 177 , at $1210-11$.

181. Measured by more permissive standards, such as the "scientific stage of verifiable certainty" test of Harper v. State, 249 Ga. 519, 525, 292 S.E.2d 389, 395 (1982), practice guidelines will readily be admissible into evidence, even where contrary guidelines from different authorities exist. The requirement of consensus is the proper standard for taking judicial notice, however, since a lesser showing of certainty would not justify removing the issue from the jury.

182. Also, for a second set of "contrary" guidelines to be relevant, they must differ on the point raised by the specific fact pattern. In the cervical cancer screening example, supra note 179, when the suit is based on improper technique in performing the test, the existence of a second set of 
Generally, it will be difficult for the retrospective testimony of individual, hired experts to ineet this standard.

General acceptance and general compliance, however, are not necessarily coextensive. Most physicians are familiar with recommended guidelines for mammography screening, yet the actual number of mammograms performed yearly falls far short of the number predicted by assuming universal comphiance with any of the recommended testing intervals. ${ }^{183}$ In such cases, judicial recognition of practice guidelines will be a deviation from the customary practice version of the standard of care. This would be a case where, in the words of Justice Hand, "a whole calling inay have unduly lagged in the adoption of new and available devices." 184 Here the standard would be not what other doctors do, but what competent, well-informed doctors ought to do. ${ }^{185}$ This deviation from the custom rule is appropriate smce the underlying justification for that rule-the mconipetence of the judge or jury to evaluate what doctors ought to do-has been supplanted by the deference to the weight of recognized medical authority. The burden then shifts to the physician to show why she deviated from the standard, and "nobody else does it" will not be a compelling defense. ${ }^{186}$ Thus a fortuitous result of my proposal is to encourage compliance with guidelines that have been determined, by the best authorities and on the best available evidence, to benefit the public health.

Following a determination of general acceptance, a court is required, under some interpretations of Frye, ${ }^{187}$ to assess the degree of acceptance by the relevant scientific community of the theoretical principles underlymg a technique (or theory) proffered as evidence. The Frye rule has been criticized on the ground that courts are incompetent to engage in this analysis. ${ }^{188}$ But again, judicial notice of practice guidelimes avoids this criticisin. By deferring on theoretical questions to the judg-

guidelines would be irrelevant since the same technique is recommended by each. In such a case, notice could be taken of the guidelines in relevant part only. The standard of care being set out by the court, the jury is left to determine whether, on the facts, the standard was met, and if not, whether any deviations were justified in the circumstances. The same logic applies where no test is done at all in circumstances where all guidelines agree that it should be done.

183. Howard, Using Mammography for Cancer Control: An Unrealized Potential, 37 CA-A CANCER J. For Clinicians 33, 35 (1987); see also Fletcher, Internal Medicine, 261 J. A.M.A. 2853 (1989) (American Cancer Society survey in 1985 found fewer than half of primary care physicians had ever ordered a screening mammogram for a patient).

184. The T.J. Hooper, 60 F.2d 737, 740 (2d Cir. 1932).

185. Cf. Johnson, Phillips, Orentlicher \& Hatlie, supra note 15, at 1385 (discussing a standard that would establish a range of reasonableness).

186. There may, of course, be many exculpatory explanations, such as the patient's refusal or noncompliance, the format of doctor-patient relationship entailed no duty on the specific facts, and others.

187. Giannelli, supra note 177 , at $1210-15$.

188. Id. 
ment of medical authorities who promulgate guidelines, courts leave judgments which may be beyond their expertise to experts most competent to make them. ${ }^{189}$ The courts' scope of decisionmaking is thereby directed to where courts are most competent-the application of rules to the facts of specific cases. Again, when technical guideline interpretation is required for proper application, impartial expert testimony can be retained to assist the court. ${ }^{190}$

A final procedural question is how the court will determine when judicial notice should be taken of practice guidelines. This was problematic for the Frye standard and led to its inconsistent application. ${ }^{191}$ For guideline judicial notice, however, the simplicity of the governing rule will permit consistent application: where the cause of action allegedly arises from behavior that belongs to a class of behaviors governed by an existing set of practice guidelines, and those guidelines have been devised by an appropriate medical authority, ${ }^{192}$ those guidelines should be judicially noticed, and the jury should accordingly be instructed on the standard of care.

Perhaps the biggest procedural advantage of the guideline notice proposal is that it does not require a radical restructuring of the present tort system, and does not impede ongoing tort reform. The evidentiary rules are already in place, both for judicial notice and for judicial use of impartial expert testimony. Courts need only be aware that judicial notice of practice standards is a procedural alternative that can expedite trials, help prevent flagrant error by juries, and reinforce the important societal policies that underlie practice guidelines, such as optimizing health resource allocation.

\section{Substantive Advantages of Judicial Notice}

In addition to the above procedural advantages, there are substantive advantages to the guideline notice proposal. Jury instruction on the practice guideline standard of care provides jurors with a much more precise guide for assessing negligence than vague notions of reasonableness and customary behavior. In this way, my proposal addresses the fundamental problem of jury competence in assessing physician behavior.

Judicial assessment of whether to notice a practice guideline and

189. Examples of theoretical principles that underlie practice guidelines and upon which courts invoking the proposed guideline notice rulc defer include: the pathophysiology of bleeding disorders, cervical carcinoma, and other relevant disease processes; principles of epidemiology; statistical analyses of screening and diagnostic tests (sensitivity, specificity, positive predictive value); principles of decision analysis; interpretation of data from clinical trials and laboratory testing; and cost-effectiveness analysis.

190. See supra note 176 and accompanying text.

191. See Giannelli, supra note 177 , at 1219-21.

192. See supra notes $121-46$ and accompanying text. 
thereby preempt the reasonable/customary standard will increase the likelihood of an accurate fit between the imposed legal standard and the actual medical standard. This follows smce, in many jurisdictions, judges are simply more sophisticated than an average jury. Certainly in all jurisdictions judges have more experience with inedical inalpractice cases and the standard of care concept. ${ }^{193}$ Furthermore, judges are better equipped than jurors to seek out objective information by asking appropriate questions of experts. Jurors must base their judgments strictly upon what counsel choose to permit them to hear, and are not permitted directly to ask questions of experts, ${ }^{194}$ or independently to retain impartial experts. These limitations on the fact-finding ability of jurors, especially when dealing with arcane, technical matters, makes them particularly ill suited to decide whether practice guidelines should be imposed as the standard of care. Thus, judicial notice of practice standards as the legal standard of care is preferable to merely admitting guidelines as evidence going to the standard, and deferring to the jury.

\section{VII}

\section{CONCLUSION}

Many commentators have called for a central policy-making body at the national level designed to formulate rational, cost-effective, outcomeoriented healtlı care policy. ${ }^{195}$ Some have urged establishment of a joint public-private entity to meet this need, ${ }^{196}$ and a strong case can be made for a governmental role in sucli a project. ${ }^{197}$

To date, lowever, no sucli program has been developed, and the cost of medical care contimues to skyrocket. To address this urgent problein, private medical societies have already made substantial progress toward establislimg medical practice guidelines based on the best available data. Comphance with these guidelines can save billions on the national health bill and simultaneously improve the quality of inedical care.

Physician confidence, lowever, is a necessary prerequisite to compliance with practice guidelines. A system that permits juries to ignore or

193. See In re Japanese Elec. Prod. Antitrust Litig., 631 F.2d 1069, 1086-87 (3d Cir. 1980) (noting that judges are always more knowledgeable than juries about litigation and legal terms and concepts).

194. Johnson, Phillips, Orentlicher \& Hatlie, supra note 15, at 1371 (citing L WE1NREB, Denial of Justice 112-13 (1977)).

195. See supra note 124.

196. See, e.g., LEADERSHIP COMMISSION REPORT, supra note 1, at 62, 64; Lohr, supra note 124; Am. Med. News, Apr. 7, 1989, at 54, col. 1 (American Medical Peer Review Association recommends public-private entity, such as the IOM, be funded to develop and implement practice guidelines).

197. Ginsburg \& Hammons, Competition and the Quality of Care: The Importance of Information, 25 INQUIRY 108, 113 (1988); see also supra notes 124-26. 
overrule these carefully designed, authoritative protocols undermines physicians' confidence. To prevent this corruption, and to promote the important public policies embodied in practice guidelines, courts should take judicial notice of applicable, authoritative practice guidelines and accordingly instruct juries on the standard of care.

To the extent that this approach assists juries in reaching correct conclusions when faced with complex, technical information, it will be an improvement over the current system of attempting to decipher the retrospective testimony of individual, hired experts. More importantly, it will give force to the social policies embodied in practice guidelines. These policies have been endorsed by the medical profession, the private sector, and by Congress, and are designed to optimize the public health in the most equitable and efficient manner possible. Courts should recognize the importance of these policies, and defer to the compelling societal interests that they address. 